\title{
Revisiting ovarian cancer microenvironment: a friend or a foe?
}

\author{
Boyi Zhang ${ }^{1}$, Fei Chen ${ }^{1}$, Qixia $\mathrm{Xu}^{2}$, Liu Han ${ }^{1}$, Jiaqian $\mathrm{Xu}^{2}$, Libin $\mathrm{Gao}^{1}$, Xiaochen Sun ${ }^{1}$, Yiwen $\mathrm{Li}^{1}$, Yan $\mathrm{Li}^{1}$, \\ Min Qian ${ }^{1}$, Yu Sun ${ }^{1,3 凶}$ \\ ${ }^{1}$ Key Laboratory of Stem Cell Biology, Institute of Health Sciences, Shanghai Institutes for Biological Sciences, Chinese \\ Academy of Sciences and Shanghai Jiao Tong University School of Medicine, University of Chinese Academy of Sciences, \\ Shanghai 200031, China \\ 2 Institute of Health Sciences, Shanghai Jiao Tong University, School of Medicine and Shanghai Institutes for Biological \\ Sciences, Chinese Academy of Sciences, Shanghai 200031, China \\ ${ }^{3}$ Department of Medicine and VAPSHCS, University of Washington, Seattle, WA 98195, USA \\ $\triangle$ Correspondence: sunyu@sibs.ac.cn (Y. Sun)
}

Received July 6, 2017 Accepted August 21, 2017

\begin{abstract}
Development of ovarian cancer involves the co-evolution of neoplastic cells together with the adjacent microenvironment. Steps of malignant progression including primary tumor outgrowth, therapeutic resistance, and distant metastasis are not determined solely by genetic alterations in ovarian cancer cells, but considerably shaped by the fitness advantage conferred by benign components in the ovarian stroma. As the dynamic cancer topography varies drastically during disease progression, heterologous cell types within the tumor microenvironment (TME) can actively determine the pathological track of ovarian cancer. Resembling many other solid tumor types, ovarian malignancy is nurtured by a TME whose dark side may have been overlooked, rather than overestimated. Further, harnessing breakthrough and targeting cures in human ovarian cancer requires insightful understanding of the merits and drawbacks of current treatment modalities, which mainly target transformed cells. Thus, designing novel and precise strategies that both eliminate cancer cells and manipulate the TME is increasingly recognized as a rational avenue to improve therapeutic outcome and prevent disease deterioration of ovarian cancer patients.
\end{abstract}

KEYWORDS ovarian cancer, stromal cells, tumor microenvironment, therapeutic resistance, ectopic metastasis, combinational treatment, patient stratification

\section{INTRODUCTION}

Ovarian cancer represents the 5th leading cause of cancerrelated death in women, which comprises a genetically and histologically broad range of tumors including those of epithelial, germ cell, and sex cord-stromal origin (Karnezis et al., 2017). One of the main facts that cause difficulty in understanding the biology and evolution of ovarian cancer is that most neoplastic cells are phenotypically not similar to their normal counterparts (Aiello et al., 2017). For high-grade serous carcinoma (HGSC), the most common ovarian malignancy usually diagnosed at an advanced stage with high mortality, no credible precursor lesion was histologically identified until 15 years ago, with the majority of mucinous ovarian cancers being in nature metastases from other organs including nearby sites such as the pancreas (Young, 2006).

Indeed, a wide variety of cancers that are not derived from normal ovarian cell types including primary ovarian neoplasia and metastatic cancers from the breast, lung, and the gastrointestinal $(\mathrm{Gl})$ tract-exist as major ovarian masses (Worzfeld et al., 2017). In contrast to the ovary which is generally understood as a fertile environment supportive of precancerous and cancerous lesions, the fallopian tube acts as a presumably inhospitable microenvironment for growth of both primary and metastatic tumors (McDaniel et al., 2015; Rabban et al., 2015). It is reasonable to speculate that the fallopian tube has evolved a tumor-suppressive microenvironment to minimize the chance of ectopic pregnancy, a condition essentially lethal until the era of surgery (Karnezis et al., 2017). Of note, the size of most ovarian malignancies, 
including primary tumors and non-gynaecological metastases, is significantly larger than the normal ovary and among the largest malignancies in the body. Although tumor stroma is usually generated de novo, the pathophysiological role of the stroma in ovarian neoplastic growth remains unclear. Earlier studies indicated that ovarian tumor stroma display both endo-crinological and morphological features of normal adult ovary, while ovarian metastases from GI tract malignancies have stroma similar to neither that of the primary GI tract tumors nor extra-ovarian metastases by containing luteinized, steroidogenic ovarian stromal cells (Scully and Richardson, 1961). Thus, the stroma of ovarian tumors histologically resembles that of normal adult ovary, and can likely provide a microenvironment that promotes the development of primary and metastatic tumors. Beyond this, comparative profiling of the transcriptomics and proteomics of ovarian tumor stroma by contrasting with those of alternative tumor types such as primary breast cancer versus ovarian metastases, may disclose stimulatory factors correlated with the preferential growth of ovary cancer as potential therapeutic targets.

Although it is well accepted that epithelial ovarian cancer cells are responsive to steroid hormone stimulation, new studies have presented the clues that the ovarian stroma may also have an active role in this process. For instance, ovarian stroma immediately adjacent to the tumor foci can express markers associated with sex-steroid differentiation and steroidogenesis (calretinin, inhibin, and steroidogenic factor 1), alongside steroid enzymes (CYP17, CYP19, HSD17ß1, and AKR1C3), while the epithelium expresses corresponding hormone receptors (Blanco et al., 2017). Thus, the epithelium-surrounding stroma in the ovary is activated to elaborate biologically relevant hormones which may enhance incontrollable neoplastic growth, although the precise mechanisms underlying these processes await further investigation. Specifically, isoform-specific alterations of Akt, the serinethreonine kinase whose 3 isoforms are encoded by distinct genes and frequently overexpressed in numerous cancers, were recently found to have divergent effects in ovarian cancer cells and the nearby microenvironment (LinnerthPetrik et al., 2016). Ablation of Akt1 in the TME generated an inhibitory effect on tumor size, without significant change in animal survival, while elimination of Akt2 or Akt3 resulted in increased tumor size, metastasis, and decreased survival time (Linnerth-Petrik et al., 2016). Although it is increasingly evident that stromal components have significant clinical implications in ovarian cancer development, recent findings uncovered an even stronger impact orchestrated by diverse cell types that may predict overall and progression-free survival of HGSC (Heindl et al., 2016). Beyond, quantitative histology-based assessments can further enable appropriate selection of patients who are in urgent need of specific therapeutic strategies including combinatorial treatments that target the heterogeneous TME (Heindl et al., 2016).
A typical TME comprises diverse non-cancerous cell lineages, including stromal fibroblasts, infiltrating leukocytes, adipocytes, neuroendocrine cells, endothelial cells, and pericytes (Chen et al., 2015). According to the specific stage of disease progression and the particular organ type, TME cells can play tumor-promoting or tumor-suppressing roles, partially depending on the adjacent cancer cells that have co-evolved. Importantly, some of the functional mechanisms through which the TME influences pathological progression are also "co-opted" to drive ectopic metastasis and therapeutic resistance in clinical settings (Klemm and Joyce, 2015).

One of the main properties that distinguish ovarian cancer from other solid tumors is the specific TME within the ovary. As ovarian cancer is a peritoneal malignancy, cancer cell dissemination is partially dependent on the peritoneal fluid as a carrier (Kipps et al., 2013). In such a case, transcoelomic dissemination is a major route of cancer cell adhesion to the omentum and serous membranes that line the peritoneal organs, generating metastatic lesions in the peritoneal cavity instead of invading through the lamina propria (Lengyel, 2010). The peritoneal environment is frequently formed by the effusion accumulating in the peritoneal cavity, which presents as large volumes of ascites (Mikula-Pietrasik et al., 2016). Typically, the ascites comprises detached cancer cells, numerous soluble factors, extracellular vesicles (EVs), various types of immune cells including $T$ cells and tumor-associated macrophages (TAMs), as well as many other host cell subpopulations, together favoring cancer cell proliferation, chemoresistance, and metastasis (Pogge von Strandmann et al., 2017). Distinct from most other human malignancies, metastases at distant sites are often confined to late stages of ovarian cancer, and the most serious problem for HGSC patients is recurrent and aggressive growth of metastatic lesions within the peritoneal cavity (Pogge von Strandmann et al., 2017). The second feature of ovarian cancer is the special relevance of the omentum, a physical structure composed of connective and fatty tissue that covers the ventral surface of the intestines. Specifically, the omentum is often the preferred site for ovarian cancer metastases and plays a key role in disease progression (Lengyel, 2010).

\section{CANCER-ASSOCIATED FIBROBLASTS}

Pathological development of ovarian cancer, from cell transformation to local tissue invasion and distant metastatic dissemination, relies on mutual communication between epithelial ovarian cancer (EOC) cells and their adjacent stromal microenvironment. An appropriate understanding of the bidirectional interaction of early EOC cells with activated stromal cells helps identify novel diagnostic stromal markers and molecular targets for clinical therapy. The stroma comprises up to $50 \%$ of the advanced ovarian tumor mass, wherein cancer-associated fibroblasts (CAFs, sharing many common features with myofibroblasts) represent a major cell 
subpopulation in the local TME (Labiche et al., 2010). By producing secretory factors such as hepatocyte growth factor (HGF), CAFs remarkably decrease sensitivity of cancer cells to various anticancer agents (Straussman et al., 2012; Wilson et al., 2012). Moreover, CAFs alter the tumor physical properties via excessive deposition and aberrant remodeling of the extracellular matrix (ECM), thus enhancing formation of an interstitial barrier that blocks efficient drug delivery (Sun, 2015). Specifically, targeting CAFs increases bioavailability of chemotherapeutic agents including doxorubicin and gemcitabine, while enabling immunological surveillance and tumor destruction through a process that engages interferon-gamma (IFNy) and tumor necrosis factor alpha (TNF- $\alpha$ ) (Kraman et al., 2010; Olive et al., 2009).

The range of biological mechanisms employed by CAFs to mediate therapeutic resistance was expanded by a recent study, which identified a novel role of CAFs in minimizing cisplatin levels within ovarian cancer cells upon chemotherapy (Wang et al., 2016). Specifically, CAF-derived glutathione and cysteine contribute to treatment resistance, which can be abolished by CD8(+) $\mathrm{T}$ cells by altering metabolism of these molecules in CAFs (Wang et al., 2016). CD8(+) T-cell-released IFNy regulates glutathione and cysteine levels via upregulation of $\mathrm{y}$-glutamyl-transferases and transcriptional inhibition of system $\mathrm{xc}(-)$ cystine and glutamate antiporter through the JAK/STAT1 axis. Importantly, the presence of stromal CAFs and CD8(+) T cells is negatively and positively correlated with the survival of ovarian cancer patients, respectively, thus capitalizing the interaction between chemotherapy and immunotherapy holds significant potential to improve treatment outcomes of ovarian cancer patients (Wang et al., 2016). As immunotherapy is emerging as a mainstay of anticancer strategies in several malignancy types including ovarian cancer, novel avenues for therapeutically targeting the pro-tumorigenic CAFs through modulation of $\mathrm{CD}^{+} \mathrm{T}$ cells are highly inspiring to both scientific and clinical communities. Although some technical issues still remain regarding how to effectively harness the TME in therapeutic settings, future studies that explore the interplay between the CAF populations and adaptive immune cells hold significant potential to provide updated approaches to integrate $\mathrm{T}$ cell therapy and/or fibroblast depletion, thereby enhancing the overall efficacy of DNA damaging chemotherapies.

During carcinogenesis, CAFs exhibit increased production and deposition of ECM components such as collagens, and are phenotypically distinguished from normal fibroblasts with enhanced expression of two CAF markers including $\alpha$ smooth muscle actin ( $\alpha-S M A)$ and fibroblast activation protein (FAP) (Schauer et al., 2011). CAFs can control epithelial cell differentiation through the secretion of multiple soluble factors, while the paracrine signaling between EOC cells and CAFs results in the release of growth, migratory and invasive signals that substantially accelerate disease progression. For example, cytokines present within medium conditioned from ES-2, an ovarian clear cell carcinoma cell line, induced transcription of urokinase-type plasminogen activator (UPA) mRNA in fibroblast cells, eventually generating enhanced urokinase implicated in cancer invasion and migration (Noskova et al., 2009). Moreover, a premetastatic niche was created in the omentum via activation and proliferation of normal fibroblasts, which were subject to stimulation by cancer cell-derived transforming growth factor $\beta 1$ (TGF- $\beta 1$ ) (Cai et al., 2012). Establishment of such a niche promoted tumor invasion at peritoneal surfaces, mainly through fibroblast release of HGF and matrix metalloproteinase 2 (MMP2). A83-01, an inhibitor of the TGF- $\beta$ type I receptor, abrogated TGF- $\beta 1$ signaling and proliferation of normal fibroblasts, accompanied by $\alpha$-SMA and MMP2 expression in tumors that contain SKOV3 cells and fibroblasts. Data from another study suggest that CAFs are present in higher abundance in advanced cancer stages, and are associated with increased density of lymphatic vessel and microvessel as well as enhanced metastasis to lymph node and omentum (Zhang et al., 2011). Specifically, CAFs isolated from ovarian cancer patients induced more significant cancer cell migration than fibroblasts from normal ovarian tissues.

Although increasing evidence suggests that selectively targeting TME cells could be a feasible approach to harness the tumor-stroma communication, identification of stromaspecific targets to make cancer cells vulnerable to therapeutic agents remains an intriguing but challenging task. To fill such a blank, a new study discovered that CAFs boost glutamine production by utilizing carbon and nitrogen from atypical nutrient sources to sustain cancer cell growth in the absence of sufficient glutamine in the TME (Yang et al., 2016). Data from an ovarian cancer orthotopic mouse model even demonstrated that co-targeting CAF glutamine synthetase and cancer cell glutaminase can disrupt such a metabolic crosstalk, inducing pronounced disease regression (Yang et al., 2016). Albeit partially uncovering the details of ovarian TME complexity, this pilot strategy is likely to synergize with multiple traditional therapies that target autonomous mechanisms of cancer cells, and holds the promise to contribute ground-breaking inputs to our ever increasing anticancer arsenal in clinics (Tajan and Vousden, 2016).

\section{MESENCHYMAL STEM CELLS}

Mesenchymal stem cells (MSCs) represent an active stromal cell subpopulation that is recruited to the TME, with prominent multipotency that allows differentiation into various cell types. In certain cases, the recruitment may be partly induced by LL-37 (leucine, leucine-37), a proinflammatory peptide of human cationic antimicrobial protein 18, and other migratory signals (Coffelt et al., 2009). Human bone marrowderived MSCs can differentiate into CAFs, which produce soluble pro-tumorigenic factors such as interleukin 6 (IL-6) to enhance tumor growth in an EOC xenograft model (Spaeth et al., 2009). Combining cancer cells and cancer-associated MSCs in vivo and in vitro causes activation of the bone 
morphogenetic protein (BMP) signaling network, which plays important roles in cancer progression (McLean et al., 2011).

Co-injection of ovarian MSCs, which secret a high level $(>2,500 \mathrm{pg} / \mathrm{mL})$ of IL-6, with SKOV3 cells enhanced tumorigenesis, sphere and colony formation in non-obese diabetic-severe combined immunodeficiency (NOD-SCID) mice, while administration of an IL-6 receptor blocking antibody minimized these malignant behaviors (Ding et al., 2016). Interestingly, cancer exosome-treated MSCs have elevated a-SMA expression, a change that indicates an activated fibroblast phenotype, alongside increased synthesis of tumor-promoting cytokines including stromal cellderived factor-1 (SDF-1) and TGF- $\beta$ (Cho et al., 2011). Thus, ovarian cancer-derived exosomes can contribute to the generation of CAFs differentiated from MSCs in tumor stroma.

Development of enhanced chemoresistance to standard clinical therapies is not uncommon in cancer patients, frequently allowing cancer cells to acquire a "cancer stem cell (CSC)-like" phenotype. This phenotypic change is usually accompanied by an epithelial-mesenchymal transition (EMT), the phenotypic switch mostly implicated in cancer metastasis. For instance, the metastatic cell line OVCA433 exhibits upregulated expression of EMT and stem cells markers (including CD44, a2 integrin subunit, CD117, CD133, EpCAM, Nanog, and Oct-4), and enhanced activation of extracellular regulated kinase 2 (ERK2) signaling upon treatment with cisplatin (Latifi et al., 2011). To the contrary, ERK2 signaling blockage by a MEK inhibitor U012 diminished expression of EMT and CSC markers, implying the potential of targeting this pathway to reduce residual tumor burden, a common cause of ovarian cancer recurrence.

Both proliferation and invasion of human EOC cells are remarkably enhanced upon co-culture with omental adiposederived MSCs (O-ADSCs) in vitro, and a recent study revealed a global increase in protein expression in the EOC cells treated with conditioned media (CM) from O-ADSC (Zhang et al., 2017). Specifically, nine proteins were identified with differential expression after $\mathrm{CM}$ treatment, which are linked to carcinogenesis, apoptosis and migration of cancer cells, suggest that O-ADSCs alter the proteomic profile of EOC cells via paracrine mechanism in favor of EOC progression (Zhang et al., 2017).

On the other hand, MSCs can be exploited as vehicles in cancer therapy, particularly when transduced with recombinant adenoviruses such as those encoding endostatin, an angiogenesis inhibitor (Jiang et al., 2010). Upon induction by SKOV3 cells in vitro, these transduced MSCs display increased capacity of migration, and can in turn generate antiproliferative effects on cancer via endostatin secretion. Furthermore, MSCs derived from human umbilical blood mononuclear cells can act as delivery vehicles for IL-21 administration to nude mice xenografted with ovarian cancer cells, a process that boosts antitcancer immunity in the murine models (Hu et al., 2011).
A new study explored the possibility of using engineered MSCs derived from adipose tissues to express either herpes simplex virus thymidine kinase (HSVtk-MSC), an enzyme that phosphorylates ganciclovir (GCV) to its toxic metabolites, or yeast fused cytosine deaminase::uracil phosphoribosyltransferase (CD::UPRT-MSC), another enzyme that converts 5-fluorocytosine (5-FC) to highly toxic 5-fluorouracil (5-FU) (Toro et al., 2016). As a result, significantly decreased tumor volumes of subcutaneous xenografts of EOC cells in nude mice and prolonged tumor-free survival in animals bearing these cancer cells after CD::UPRT-MSC/5-FC treatment were achieved. Taken together, these studies provide supporting evidence for the potential utility of MSCs as gene delivery vehicles that can be incorporated into future therapeutic strategies. Nevertheless, the possibility for MSCs to undergo either malignant transformation or differentiation into pro-tumorigenic fibroblasts can limit their roles in multiple clinical settings, thus future research is eagerly awaited to overcome these barriers and translate the medical value of MSCs in clinics.

\section{OVARY-ASSOCIATED ADIPOCYTES}

For years, adipocytes are considered as energy producing and storing residents of fat tissue in the TME (Miranda and Ahmed, 2017). However, recent studies indicate that adipocytes may have other pathophysiological functions, and their interactions with cancer cells have been reported in breast, ovarian, colon, and gastric malignancies (Nieman et al., 2011). So far, tumor-promoting effects of adipocytes are linked to their secretion of adipokines, hormones, and growth factors including matrix metalloproteinase 11 (MMP11), IL-6, $\mathrm{IL}-1 \beta$ into the surrounding TME, which collectively enhance the migration and invasion capacity of cancer cells (Dirat et al., 2011). In addition, upon co-culture with breast cancer cells, adipocytes exhibit an activated phenotype characterized by enhanced production of proteases and cytokines including IL- 6 and IL-1 $\beta$, as well as delipidation and a loss of adipocyte-associated markers. Further, peritumoral adipocytes exhibit an altered phenotype with specific biological features that are sufficient to allow these cells to be named cancer-associated adipocytes (CAA) (Dirat et al., 2011). Normal adipocytes stimulate the migration and invasion of cancer cells that are estrogen receptor (ER)-negative, a process mediated via a cytoskeletal element cofilin-1 and increased IL-6 secretion in adipocytes (Walter et al., 2009). Beyond the adipose tissue, pre-adipocytes also reside in the bone marrow and stromal compartments of other organs such as skin (Schmidt and Horsley, 2013). Interactions between mesenchymal stroma and the underlying adipose tissue allow generation of MSCs and cytokines, each frequently triggering stromal cell senescence and increasing therapeutic resistance (Ackerman and Simon, 2014; Sheng and Mittelman, 2014; Tchkonia et al., 2010). A new study exploring the mechanism of resistance to mitochondria-initiated apoptosis in EOC cells uncovered that adipocyte- 
induced upregulation of $\mathrm{Bcl}_{\mathrm{xl}}$ in EOC cells was correlated with acquired chemoresistance, illustrating a novel pathway that allows the TME to modulate apoptosis-associated protein expression and confers chemoresistance on malignant cells (Cardenas et al., 2017).

A study using fluorescence technique to show the preferential migration of ovarian cancer cells to the mouse omentum revealed that cancer cell migratory behavior can be mediated by adipokines secreted by omentum-associated adipocytes, including chemokine $\mathrm{C}-\mathrm{C}$ motif ligand 2 (CCL2), IL-6, IL-8, tissue inhibitor of metalloproteinase 1 (TIMP1), and adiponectin (Nieman et al., 2011). Of note, coculture of adipocytes and ovarian cancer cells induced adipocyte-specific lipolysis, allowing the transfer of free fatty acids to cancer cells which in turn accelerated tumor growth through energy generation via $\beta$-oxidation. In addition, adipocyte-derived hormones such as leptin are associated with increased proliferation of ER-positive ovarian cancer cells, while ER $\alpha$ can be transcriptionally activated through the signal transducer and activator of transcription-3 (STAT3) signaling pathway, suggesting that both ER status and growth promoting properties of adipocytes need to be considered in obese ovarian cancer patients (Choi et al., 2011).

As adipokines can control multiple key processes including appetite, body temperature, blood clotting, energy expenditure, glucose homeostasis, inflammation, insulin sensitivity, reproduction, ageing and cancer (Bravo-Sagua et al., 2016), increasing studies begin to explore the functional roles of these circulating adipocyte-secreted factors in human cancer. To date, diverse adipokines such as adiponectin, leptin, resistin, plasminogen activator inhibitor-1 (PAI1), vascular endothelial growth factor (VEGF), TNF- $\alpha$, IL-6, autotaxin, fatty acid-binding proteins (FABPs) are being extensively investigated (Guaita-Esteruelas et al., 2017). Among them, adipose-derived FABP4 and FABP5 are identified as critical proteins particularly in lipid-related metabolic processes upon their overexpression in human malignancies including breast, prostate, colorectal, and ovarian cancers. For instance, CAAs interact metabolically with cancer cells through fatty acid transport via FABP4 in ovarian cancer, while FABP4 is involved in lipid transfer between adipocytes and cancer cells, a process that engages the fatty acid oxidation pathway to aid in cancer progression (Nieman et al., 2013). Interestingly, FABP4 knockdown in endothelial cells causes increased fatty acid oxidation and reactive oxygen species (ROS) generation, but decreased angiogenesis, growth, and metastasis in ovarian tumor xenografts (Harjes et al., 2017). Usually, high FABP4 expression levels in human primary tumors are correlated with elevated incidence of residual disease relapse after primary debulking surgery of HGSC, raising the possibility of exploring FABP4 as a candidate biomarker of residual disease in this condition (Tucker et al., 2014).

A recent in vivo time-course study disclosed the inverse relationship between metastatic rate and omental adipocyte content, while both milky spots and adipose tissues have specific roles in colonization of the omentum by ovarian cancer cells (Clark et al., 2013). Due to physical proximity to the primary abdominal malignancies, adipose tissues from the peritoneal cavity are frequently observed as a metastasis site for colorectal, gastric, pancreatic, uterine, and ovarian cancers (Guaita-Esteruelas et al., 2017). Obesity contributes to ovarian cancer metastasis, and there is a negative correlation between obesity and survival of ovarian cancer patients (Liu et al., 2015). Ovarian cancer cells that have metastasized to adjacent adipose tissues have upregulated expression of genes encoding fatty acid transport proteins such as CD36 and FABP4, together with other molecules including CD31, CD34, VEGFR1, and VEGFR2 (Gusky et al., 2016). Unlike many solid malignancies, HGSC rarely metastasizes outside the adipocyte-rich abdominal cavity (Kobayashi et al., 2017). A recent study discovered that saltinducible kinase 2 (SIK2) overexpressed in adipocyte-rich metastatic deposits promotes abdominal metastasis, while adipocyte-induced calcium-dependent activation and autophosphorylation of SIK2 not only augments adenosine monophosphate-activated protein kinase (AMPK)-induced acetyl-CoA carboxylase phosphorylation but also activate the PI3K/AKT pathway via p85a-S154 phosphorylation (Miranda et al., 2016). The data identified SIK2 as a key molecule at the hub of the adipocyte-induced signaling cascades and provided a strong rationale for targeting SIK2 in ovarian cancer therapy.

\section{TUMOR-ASSOCIATED MACROPHAGES}

Although recruitment of tumor-infiltrating leukocytes is one of the natural immune responses to tumorigenesis, numerous studies have identified that distinct leukocyte populations except lymphocytes, are indeed tumor promoting rather than tumor suppressing (Lu et al., 2017). Lymphocytic infiltration is associated with favorable prognosis and improved rates of both progression-free and overall survival of EOC patients (Sato et al., 2005b; Zhang et al., 2003). In particular, the presence of lymphocyte markers including CD20, FoxP3, and $T$ cell intracellular antigen-1 (TIA-1) are indicators of positive prognosis for patients manifesting HGSC (Milne et al., 2009), indicating recruitment of distinct populations of $T$ cells to the tumor site to generate cytotoxic effects. Despite the presence of immune-associated anticancer activities in the TME, most cancer cells can manage to escape immune surveillance. For example, Hospicells expressing the cell surface markers CD9, CD10, CD29, CD146, and CD16 in stroma produce a large amount of nitrous oxide (NO), which suppresses CD4(+), CD8(+) and Vү9Vס2 T cell proliferation and cytokine production, eventually conferring chemoresistance on ovarian cancer cells (Martinet et al., 2010). Thus, targeting Hospicells can be an alternative approach to strengthen the efficacy of chemotherapy via recovery of immune responses against cancer cells.

Cancer cells and macrophages have bidirectional interactions through the exchange of soluble factors, a process 
that remarkably influences the behavior and phenotype of both cell populations. By exploring the contribution of stromal cell-released MMP9 to ovarian tumor growth, a former study showed that cancer cells can change macrophage secretion of cytokines, chemokines, MMPs to enhance tumor growth in peritoneal cavities of nude mice (Huang et al., 2002). As supporting evidence, M2 macrophage (or tumor-associated macrophage, TAM)-secreted MMP9 promotes release of membrane-associated heparin-bound epidermal growth factor (HB-EGF) from the same cells, a process that increases expression of MMP9 in OVCA433 ovarian cancer cells, generating a positive feedback loop to drive growth factor release and accelerate proliferation via co-culture (Carroll et al., 2016). Compared with MMP9(+/+) mice, MMP9(-/-) animals implanted with human ovarian cancer cells have decreased microvessel density and macrophage infiltration into the lesions (Huang et al., 2002). As supporting evidence, upon co-culture of TAMs and ovarian cancer cell line SKOV3, TAMs significantly upregulated MMP2, MMP9, and MMP10 expression and enhanced SKOV3 cell invasion via TLRs signaling pathway, validating the positive association of TAMs with metastasis and advancement of human ovarian cancer (Ke et al., 2016).

In addition, ovarian cancer cells induce dynamic changes in macrophage cytokine, chemokine, and MMP mRNA, and protein-inducing mediators observed in human cancer patients, forming a phenotype similar to that of TAM (Hagemann et al., 2006). Additionally, scavenger receptor expression is also reduced in TAM from ovarian tumors treated with TNF- $\alpha$ antibodies or developed in TNF- $\alpha(-/-)$ mice, indicating chemical communication between cancer cells and macrophages as an important factor in regulating the local microenvironment (Hagemann et al., 2006). A transcriptome-wide global map of signaling pathways in the ovarian TME associated with clinical outcome was recently established via investigation of cancer cell- and TAM-specific transcriptomes from ovarian cancer ascites. STAT3-inducing cytokines, fibroblast growth factor (FGF), and WNT signaling pathway components, semaphorin axon and ephrin guidance proteins, and BMP/TGF- $\beta$-activated axis, are evidently associated with early relapse (Reinartz et al., 2016). In addition, TAM-derived phospholipase A2 group VII (PLA2G7) and its product arachidonic acid (AA), together with the AA metabolites including prostaglandin E2 (PGE2), prostaglandin I receptor (PGI2), and leukotriene B4 (LTB4)associated signaling pathways are also correlated with disease recurrence, indicating a signaling network that operates in the ovarian TME with previously unknown pathway constituents of clinical relevance (Reinartz et al., 2016).

Polarization of macrophages and monocytes toward an M2 phenotype can be promoted by coagulation factor XII (FXII), thrombin, leukemia inhibitory factor (LIF), IL-6 or colony stimulating factor-1 (CSF1), each creating an immune-deficient microenvironment (Alvero et al., 2012; Duluc et al., 2007; Wang et al., 2010; Zhang et al., 2010). Although TAM interferes with normal $T$ lymphocyte generation and function, contributing to tumor tolerance as a tumor-trophic cell lineage, some immunological factors are able to reverse these TAM-specific immunosuppressive properties. In the presence of ovarian ascites, IFNy skews monocyte differentiation from TAM and turn them into M1polarized immune-competent macrophages, suggesting that IFNy overrides TAM-induced immunosuppression by preventing TAM generation and that IFNy holds the potential to enhance the effectiveness of anticancer immunotherapies by promoting the expansion of effector T cells (Duluc et al., 2009).

Rat $\lg E$ and $\lg G$ monoclonal antibodies specific for the folate receptor (FRa), a protein expressed on human ovarian cancer cells, can markedly reduce lung metastases (Josephs et al., 2017). This change is accompanied by increased $\mathrm{TNF}_{-} \mathrm{\alpha}^{+}$and $\mathrm{CD}^{+} 0^{+}$macrophage infiltration, together with elevated TNF- $\alpha$ and the monocyte chemotactic protein 1 (MCP-1, or CCL2) in bronchoalveolar lavage fluid of the lung, suggesting anticancer IgE reprograms macrophages in the TME (Josephs et al., 2017).

Although there are similarities between TAMs from human ovarian carcinoma ascites, monocyte-derived macrophages (MDMs) and resident peritoneal macrophages (pMPHs), a recent study identified a TAM-specific signature of 30 genes, which are upregulated as opposed to both MDMs and pMPHs and associated with ECM remodeling, indicating a distinct role for TAMs in ovarian cancer invasion and metastasis (Finkernagel et al., 2016).

A recent study explored the relationship between cancer cell-secreted exosomes and TAM polarization under hypoxic conditions, and found hypoxia increases microRNA-940 (miR940) expression in exosomes derived from EOC cells (Chen et al., 2017). Interestingly, uptake of exosome-delivered miR940 in macrophages stimulated an M2 polarization, while the M2 subtype macrophages (TAMs) further enhanced EOC proliferation and migration. Furthermore, TAM-derived exosomes can target the miR-146b-5p/TRAF6/NF-kB/MMP2 pathway to inhibit endothelial cell migration, a process that is subject to reversal by long non-coding RNAs (IncRNAs) delivered by SKOV3-released exosomes (Wu et al., 2017b).

To date, many efforts are made to target TAMs, and some have shown promising potential in anticancer regimens. Synthesis of tumor-promoting factors including CCL2 and IL-6 is minimized in TAMs and ovarian cancer cells upon treatment by Trabectedin (Yondelis), an agent that originates from the tunicate Ecteinascidia turbinate, binds DNA minor grooves and inhibits monocyte differentiation into macrophage (Allavena et al., 2005). The inhibitory effect of Trabectedin on macrophage differentiation, viability, and cytokine production contributes to its anticancer activity in inflammation-associated human tumors. A phase II study on 147 patients with ovarian cancer who had the experience of platinum-containing chemotherapy, consolidated Trabectedin as an active agent in ovarian cancer clinics (Musrap and Diamandis, 2012; Simpson, 2007) (Table 1). However, the vast majority of these patients reported toxic effects, 
Table 1. Therapeutic agents that target the tumor microenvironment in clinical trials

\begin{tabular}{|c|c|c|c|c|}
\hline Drug/Agent & Type & Target/Mechanism & Impact on the TME & $\begin{array}{l}\text { Stage in } \\
\text { clinical } \\
\text { trials }\end{array}$ \\
\hline Infliximab & $\begin{array}{l}\text { Monoclonal } \\
\text { antibody }\end{array}$ & Binds to TNF- $\alpha$ with high affinity & $\begin{array}{l}\text { Decreases levels of pro-inflammatory } \\
\text { cytokines }\end{array}$ & Phase 1 \\
\hline Etanercept & $\begin{array}{l}\text { p75 TNF } \\
\text { receptor } \\
\text { fusion } \\
\text { protein }\end{array}$ & TNF- $\alpha$ blocker & Inhibits actions of TNF- $\alpha$ & Phase 2 \\
\hline Siltuximab & $\begin{array}{l}\text { Monoclonal } \\
\text { antibody }\end{array}$ & Neutralizes IL-6 & Inhibits functional activity of IL-6 & Phase 3 \\
\hline Trabectedin & $\begin{array}{l}\text { Tetrahydro- } \\
\text { isoquinoline } \\
\text { alkaloid }\end{array}$ & $\begin{array}{l}\text { Binds minor groove of DNA, } \\
\text { preventing cell cycle completion; } \\
\text { causes apoptosis }\end{array}$ & $\begin{array}{l}\text { Inhibits monocyte-to-macrophage } \\
\text { differentiation; decreases production of } \\
\text { pro-tumoral cytokines }\end{array}$ & Phase 3 \\
\hline Sibrotuzumab & $\begin{array}{l}\text { Monoclonal } \\
\text { antibody }\end{array}$ & Binds to FAP & $\begin{array}{l}\text { Targets major constituents of tumor } \\
\text { stroma }\end{array}$ & Phase 2 \\
\hline Volociximab & $\begin{array}{l}\text { Monoclonal } \\
\text { antibody }\end{array}$ & Binds $\alpha 5 \beta 1$ integrins & $\begin{array}{l}\text { Blocks cancer cell attachment to } \\
\text { mesothelium }\end{array}$ & Phase 2 \\
\hline Bevacizumab & $\begin{array}{l}\text { Monoclonal } \\
\text { antibody }\end{array}$ & Binds all isoforms of VEGFA & Suppresses angiogenesis & Phase 3 \\
\hline
\end{tabular}

Representative therapeutic agents that target specific components of the TME and are currently in cancer clinical trials. Data adapted from Musrap and Diamandis with permission from Molecular Cancer Research, copyright 2012, with agent stage-relevant information updated to the date of publication.

including fatigue, granulocytopenia, nausea and vomiting, suggesting that definition of a possible role for this drug requires continued investigation (Fig. 1).

\section{OTHER INNATE IMMUNE CELLS}

In addition to TAMs, other innate immune cell subsets are also essential and can generate efficient but mechanistically distinct tumor-associated influences on the development of ovarian cancer. A former study indicated that the tumor-associated inflammatory mediator PGE2 attracts myeloid derived suppressor cells (MDSCs) into ascites of ovarian cancer patients, a process dependent on the expression of C-X-C chemokine receptor type 4 (CXCR4) and its ligand CXCL12 in the ascites microenvironment (Obermajer et al., 2011). The study revealed that frequencies of CD11b(+) CD14(+)CD33(+)CXCR4(+) MDSC migration closely correlates with PGE2 and CXCL12 levels in patient ascites, suggesting a central role for PGE2 in MDSC accumulation regulated by the CXCL12/CXCR4 pathway and providing a novel rationale to target PGE2 signaling in ovarian cancer treatment (Obermajer et al., 2011).

Moreover, MDSCs produce a substantial amount of IL-10, which allows to form an immunosuppressive in vivo niche, implying the critical role of IL-10 for development of a tumorpermissive TME (Hart et al., 2011). Further, IL-10 plays a unique role that is not redundant with those of other immunosuppressive molecules, as IL-10 signaling blockade alleviates MDSC-mediated immunosuppression and improves survival, defining $\mathrm{IL}-10$ as a fundamental immune cell modulator in the ovarian TME and represents a viable target for therapeutic strategies (Hart et al., 2011). Although the molecular pathways associated with the differentiation and function of MDSCs in tumorigenesis have been reported (Condamine et al., 2015), the specific mechanisms that recruit MDSCs to the primary tissue and ovarian cancer ascites remain largely unclear.

Natural killer (NK) cells compose another important subset of innate immune cells that actively recognize and eliminate cancer cells. CD16 receptor, NKG2D receptor and natural cytotoxicity receptors, mediate NK-dependent immune surveillance in the TME. In ovarian cancer ascites, two main pathways that suppress NKG2D and NKp30 activity have been recognized. Specifically, migration inhibitory factor (MIF) promotes the immune escape of ovarian cancer cells by transcriptionally down-regulating NKG2D in vitro and in vivo, thus impairing NK cell cytotoxicity towards neoplastic cells (Krockenberger et al., 2008). Enhanced expression of B7-H6, the recently identified B7 family member as a ligand for NKp30 on NK cells, is positively correlated with ovarian cancer metastasis (Zhou et al., 2015). However, NK cells from patients of low NKp30 expression display decreased IFNy production and reduced cytolytic function in targeting cells that express surface B7H6, suggesting a novel mechanism that allows the TME to promote cancer cell escape from immune surveillance (Pesce et al., 2015). A recent study reported the functional difference between NK cells in EOC cell-free ascites and 


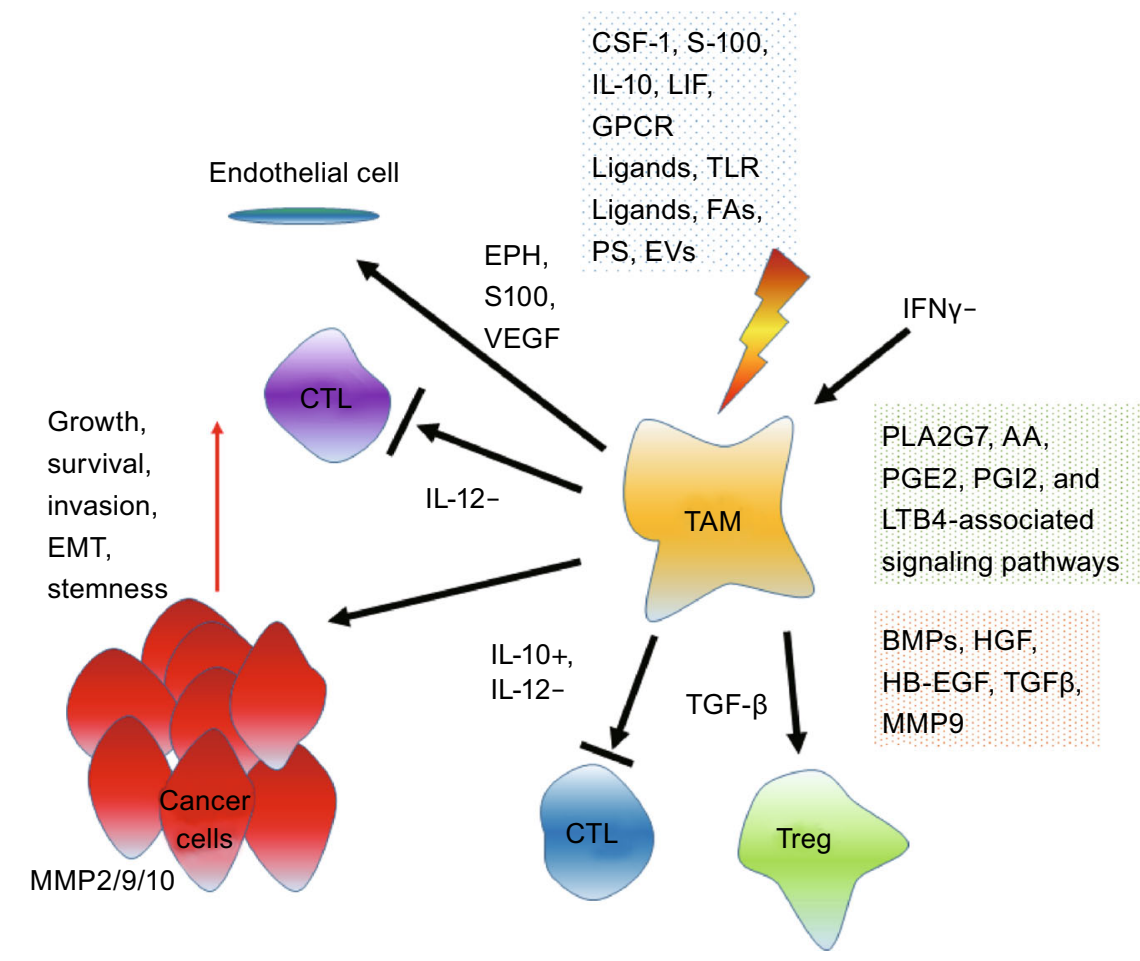

Figure 1. Functional implications of tumor-associated macrophages (TAMs) in the ovarian cancer microenvironment. Presence of multiple mediators in the TME and lack of interferon y (IFNY) allow activation of TAMs. In response to various stimuli, TAMs release diverse soluble factors that impinge on ovarian cancer cells and resident host cells while minimizing the expression of essential anticancer factors such as IL-12. CSF1, colony stimulating factor 1; LIF, leukemia inhibitory factor; GPCR, G protein coupled receptor; TLR, toll-like receptor; FA, fatty acid; PS, phosphatidylserine (PS); EV, extracellular vesicle; AA, arachidonic acid; PGE2, prostaglandin E2; PLA2G7, phospholipase A2 group VII; PGI2, prostaglandin I receptor; LTB4, leukotriene B4; BMP, bone morphogenetic protein; HGF, hepatocyte growth factor; HB-EGF, heparin-bound epidermal growth factor; TGF- $\beta$, transforming growth factor $\beta$; MMP, matrix metalloproteinase; EMT, epithelial-mesenchymal transition; CTL, cytotoxic T lymphocyte; Treg, regulatory $T$ cell; EPH, ephrin; S100, S100 calcium binding protein; VEGF, vascular endothelial growth factor; IL-12-, IL-12 reducing; IL-10+, IL-10 enhancing.

those in ascites with EOC cells, while impaired NK cell response to IL-2 in ascites containing EOC cells is indicative of an immunosuppressive TME (da Silva et al., 2017).

Upon exposure to either inflammatory factors including IFNa, IL-15, IL-12 and IL-2, or ovarian cancer cells, NK cells primed by IL-18 can release chemokines CCL3 and CCL4 to attract immature dendritic cells (iDCs) (Wong et al., 2013). Crosstalk between NK and DC via a CCR5-dependent mechanism causes upregulation of CCR5 and CXCR3 ligands (CCL5, CXCL9, and CXCL10) on DC cells, stimulating recruitment of type-1 effector CD8(+) T (Teff) effector $T$ cells to the TME (Wong et al., 2013). Thus, NK cell activation is critical for elimination of target cancer cells and development of an anticancer immune response. As an interesting point, an IL-15 super-agonist complex ALT-803ALT-803 enhances NK cell cytotoxicity against ovarian cancer and can rescue functionality of NK cells isolated from ovarian cancer patient ascites, suggesting that ALT-803 has the potential to enhance NK cell-based immunotherapeutic efficiency for ovarian cancer treatment (Felices et al., 2017).

\section{T LYMPHOCYTES}

Enhanced infiltration of tumor-infiltrating lymphocytes (TILs) is associated with increased levels of cytokine IFNy, a prognostic factor that indicates better survival for ovarian cancer patients (Zhang et al., 2003). Specifically, high frequency of intraepithelial $\mathrm{CD}^{+} \mathrm{T}$ cells expressing the $\alpha \mathrm{E}$ integrin subunit CD103, which may serve as a novel marker for enriching the most beneficial subsets of TILs for immunotherapy, correlates with enhanced survival in ovarian cancer, suggesting that $\mathrm{CD}^{+} \mathrm{T}$ lymphocytes directly contribute to the anticancer effects (Komdeur et al., 2016; Sato et al., 2005b; Webb et al., 2014). However, CD4 ${ }^{+}$T cells minimized the beneficial effects of $\mathrm{CD} 8^{+} \mathrm{T}$ cells through CD25(+) forkhead box P3 (FOXP3)(+) regulatory T cells (Treg, suppressor T cells), as evidenced by the significantly shortened median survival of patient subgroups that had high $\mathrm{CD}^{+}$versus $\mathrm{CD}^{+} \mathrm{T}$ cell ratios (Sato et al., 2005a). Data from combined cytokine studies, neutralization experiments, and proliferation assays unveiled that induction of 
CD8(+) Tregs under in vitro conditions relies at least partially on TGF- $\beta 1$ to exert their suppressive function, a process that is critically mediated by activation of p38MAPK, suggesting p38MAPK as a potential therapeutic target in ovarian cancer immunotherapy (Wu et al., 2016a).

Beyond controlling autoimmunity, allergy, and inflammation in mammals, Tregs are responsible for the maintenance of immune homeostasis in the course of host response to tumorigenesis (Geis et al., 2015). Specifically, Tregs inhibit the proliferation of $\mathrm{CD}^{+}$T cells as well as their production of IFNy and IL-2, counteract the protective effect of cytotoxic T cells in ovarian cancer tissues, thus reversely correlated with patient survival (Curiel et al., 2004). Moreover, the ovarian cancer microenvironment can induce migration of CTLA4 ${ }^{+}$ FOXP3 $^{+}$GITR $^{+}$Tregs via the chemokine CCL22 and its receptor CCR4, the latter expressed by infiltrating Tregs (Curiel et al., 2004; Landskron et al., 2015). Importantly, Tregs in the malignant ascites are more activated and proliferate faster than blood-derived cells from the same patient, while the Treg number in patient ascites positively correlates with the epithelial cell number in effusion (Landskron et al., 2015). Interestingly, there is interaction between Treg cells and TAMs in the TME of epithelial ovarian cancer, as is evidenced by a recent study reporting that IL-10 released by TAMs enhances the frequency of Treg cells via activation of Foxp3 during T-cell differentiation and accelerates disease progression (Zhu et al., 2016).

As Tregs suppress tumor-specific $\mathrm{T}$ cell immunity and contribute to cancer cell expansion, a strategy exploited by cancer cells to escape immune surveillance, interfering with Treg migration or their function may help prevent disease from further exacerbation. For instance, an anti-CCR4 antibody mAb2-3 blocks Treg migration and stimulates IFNY secretion by $\mathrm{CD}^{+} \mathrm{T}$ cells, eventually enhancing anticancer response in an experimental model bearing CCL22-secreting ovarian cancer cells (Chang et al., 2016). As mAb2-3 induces CD25 shedding from Tregs and causes decreased IL-2-dependent survival of these animals, mAb2-3 represents a promising agonist antibody to restore anticancer immunity by modulating Treg activity (Chang et al., 2016). Interestingly, CD8 ${ }^{+}$Treg cells co-cultured with SKOV3 have lower glycolysis-associated gene expression than $\mathrm{CD}^{+} \mathrm{T}$ cells cultured alone (Wu et al., 2016b). As the glycolysisrelated gene expression pattern is also minimized in the $\mathrm{CD}^{+} \mathrm{T}$ cells of ovarian cancer patients, tumor-stroma mutually remodeled metabolic processes may be a potential mechanism for $\mathrm{CD}^{+}$Treg induction and reprogramming (Wu et al., 2016b).

Malignant ascites represents a proinflammatory and immunosuppressive reservoir enriched in chemokines, cytokines, growth factors, and immune cells which together form a pro-tumorigenic microenvironment that allows tumor cell growth and confers resistance to standard treatments (da Silva et al., 2017). However, a new study disclosed that co-treatment with dabigatran etexilate, a direct thrombin inhibitor, significantly promoted the genotoxic activity of cisplatin during ovarian cancer progression via alleviation of the immunosuppressive microenvironment, suggesting that thrombin may be a candidate therapeutic target for ovarian cancer patients (Alexander et al., 2016). Another study explored the effect of neoadjuvant chemotherapy (NACT) on immune activation in stage IIIC/IV tubo-ovarian HGSC, and found that NACT enhanced host immune response but can be interfered by high levels of PD-1, PD-L1 and CTLA4, implying sequential chemoimmunotherapy may provide therapeutic benefits in advanced HGSC populations (Bohm et al., 2016). Data from clinical investigation of ovarian cancer-associated $\mathrm{CD}^{+} \mathrm{CD} 25^{+}, \quad \mathrm{CD} 4^{+} \mathrm{CD} 25^{+} \mathrm{Foxp}^{+}$, $\mathrm{CD} 8^{+} \mathrm{CD} 28^{-}$, and $\mathrm{CD}^{+}{ }^{+} \mathrm{Foxp} 3^{+}$Tregs and their postoperative alterations indicated that Tregs percentage continues to decline in postoperative period with remarkable correlation with the tumor burden, thus can be used as an important factor in monitoring the immunological status of ovarian cancer patients (Wu et al., 2017a) (Fig. 2).

\section{ANGIOGENESIS AND NEOVASCULATURE}

In the TME, cancer cells rely on a constant supply of nutrients and oxygen, which is supported by the formation of new blood vessels. Several pathways are involved in the regulation of the growth and maintenance of neovasculature, a process that can be mediated by proangiogenic factors secreted by both tumor and stromal cells (Saharinen et al., 2011). MMP1-mediated activation of the $G$ protein coupled receptor (GPCR) protease-activated receptor-1 (PAR1) stimulates ovarian cancer cells to release CCL2, IL-8, growth regulated oncogene-a (GROa), chemokines that induce endothelial cell proliferation, tube formation, angiogenesis, and metastasis in peritoneal mouse models of ovarian cancer (Agarwal et al., 2010).

A new study examined VEGF expression in benign, borderline, and malignant neoplasms to correlate it with histological grade and stage of ovarian cancer patients. Despite notable VEGF expression in some benign and borderline neoplasms, high VEGF expression was mostly observed in carcinomas, suggesting EOC as a candidate for VEGF-targeting therapy (Mukherjee et al., 2017). Although the globally commercialized VEGF-specific antibody, Avastin, displayed effectiveness in suppressing angiogenesis in these animals, IL-8 and GROa-dependent endothelial tube formation in vitro remained unchanged (Agarwal et al., 2010). Another study identified tumor necrosis factor superfamily-15 (TNFSF15), an endogenous suppressor of neovascularization, plays a critical role in the physiologically normal ovary but is lost in ovarian cancer (Deng et al., 2012). TNFSF15 silencing before and after inoculation of ovarian cancer ID8 cells to mice markedly increases angiogenesis and tumor growth, suggesting downregulation of TNFSF15 by cancer cells and tumor infiltrating macrophages (TIMs) and lymphocytes is a prerequisite for neovascularization in ovarian cancer (Deng et al., 2012). 


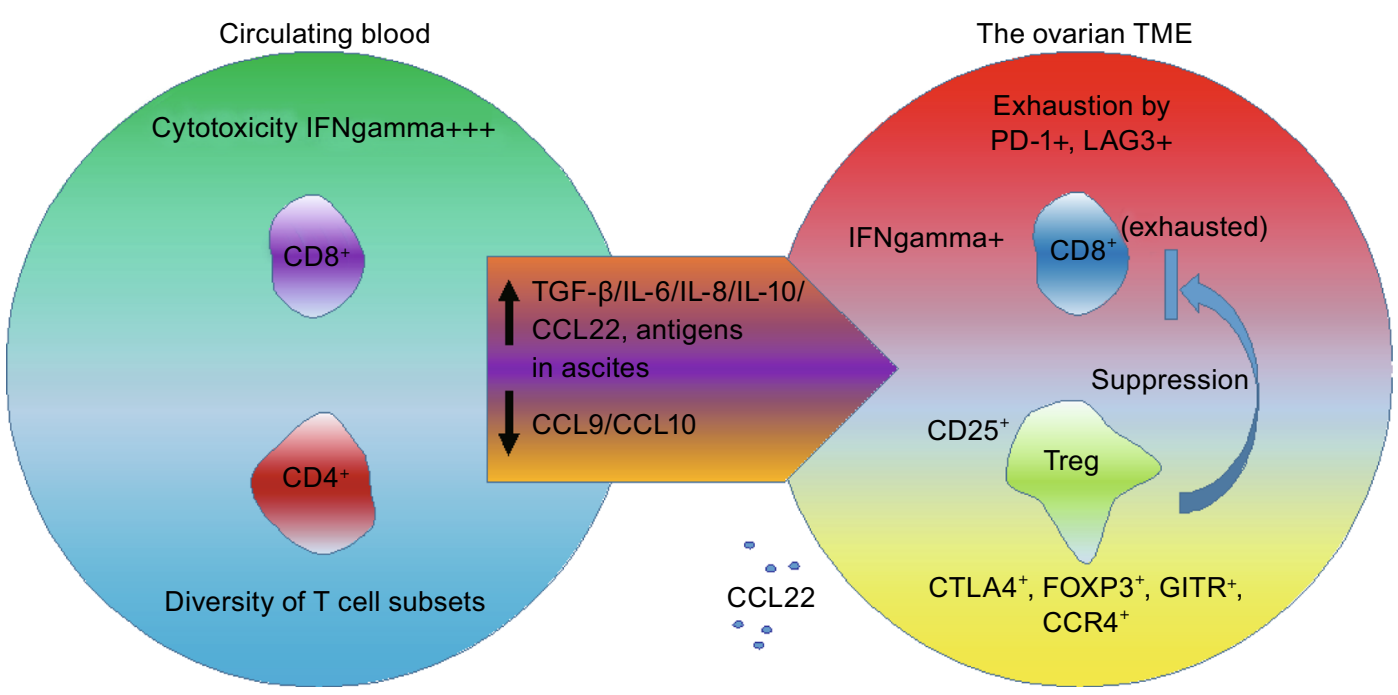

Figure 2. The balance between $\mathrm{CD}^{+} \mathrm{T}$ cell and Treg cells in the ovarian cancer microenvironment. Signals provided by cytokines present in ovarian cancer ascites (IL-6, IL-10) and by dendritic cells induce exhaustion of CD $8^{+}$T cells. Cells co-expressing the inhibitory receptors, programmed cell death protein 1 (PD-1) and lymphocyte activation gene 3 (LAG3), exhibit significant impairment in the production of interferon $y$ (IFNy) and tumor necrosis factor $\alpha$ (TNF- $\alpha)$. Specifically, high antigen concentrations in the ascites can induce $\mathrm{CD}^{+} \mathrm{T}$-cell exhaustion. Moreover, impaired expression of the T helper 1-associated chemokines CCL9 and CCL10 weaken the migration of $\mathrm{CD}^{+} \mathrm{T}$ cells into the TME. However, the preferential migration of immunosuppressive $\mathrm{FOXP}^{+} \mathrm{CTLA}^{+}, \mathrm{GITR}^{+} \mathrm{CCR} 4^{+}$Tregs is stimulated by the chemokine CCL22. CD4 ${ }^{+}, \mathrm{CD} 4$ positive; CD8 ${ }^{+}, \mathrm{CD}$ positive; $^{\circ}$ 2 $25^{+}$, CD25 positive; CTLA4 ${ }^{+}$, cytotoxic T-lymphocyte associated protein 4 positive; Treg, regulatory T cell; GITR ${ }^{+}$, TNF receptor superfamily member 18 positive; FOXP3 ${ }^{+}$, forkhead box P3 positive; IL-6, interleukin 6; IL-8, interleukin 8; IL-10, interleukin 10; $\mathrm{CCR}^{+}, \mathrm{C}-\mathrm{C}$ motif chemokine receptor 4 positive; CCL9, C-C motif chemokine ligand 9; CCL10, C-C motif chemokine ligand 10; CCL22, C-C motif chemokine ligand 22.

Pericytes, endothelial, and smooth muscle cells are stromal components that play an essential role in angiogenesis (Bussard et al., 2016; Huijbers et al., 2016). Although pro-angiogenic factors are produced by stromal and epithelial cells during early carcinogenesis or as a consequence of inflammation, enhanced angiogenesis is usually a late event in cancer progression (Hanahan and Weinberg, 2011). Upon treatments by anticancer agents, stromal expression of VEGF and other angiogeneic factors including angiopoietin 1 (ANGPT1) and angiopoietin-like 4 (ANGPTL4) is increased, functionally stimulating vasculature development within the drug-remodeled TME (Coppe et al., 2008; Sun et al., 2012). Synthesis of the secreted frizzledrelated protein 2 (SFRP2), a canonical modulator of Wnt signaling, is enhanced in damaged prostate stroma by chemotherapeutics, which promotes angiogenesis via a calcineurin/NFAT pathway in a non-canonical manner (Courtwright et al., 2009; Siamakpour-Reihani et al., 2011). Of note, SFRP2 acts as an agonist of WNT16B, another extracellular factor released by the therapy-damaged TME which significantly promotes drug resistance of residual cancer cells in human prostate, breast, and ovarian malignancies in post-treatment stage (Sun et al., 2012; Sun et al., 2016) (Fig. 3). Increasing interest has emerged in targeting angiopoietin growth factors (mainly Ang1, Ang2, Ang4) that promote CAF accumulation and tumor angiogenesis in the
TME, while Tie1 and Tie2 (also as TEK) receptors that regulate the maturation and plasticity of blood vessels are also considered as valuable targets (Augustin et al., 2009; Brunckhorst et al., 2014). Anti-angiogenic therapies targeting tumor vasculature represent a practical approach upon combination with other conventional treatments in ovarian cancer management. Minimizing angiogenesis in cancer patients to overcome side effects caused by cytotoxicity is thus a promising strategy to block neoplastic growth and deprive cancer cells of microenvironment-conferred malignancy.

Continuous accumulation of ascites, chronic inflammation, and elevated VEGF concentrations are among the typical hallmarks of ovarian cancer progression. Overexpressed c-myc remarkably enhances VEGF concentrations in ascites of ovarian cancer mice, while transduced Kras significantly enhances inflammatory cytokine concentrations and increases the number of neutrophils in animal ascites, suggesting that oncogenes can favor disease progression by modulating the ovarian TME (Yoshida et al., 2016). Moreover, peritoneal cavity and retroperitoneal lymph node represent main routes for EOC dissemination, while VEGFmediated angiogenesis is an important mechanism that promotes ovarian cancer progression. As patients with high VEGFC levels display a significantly worse overall survival than those with low VEGFC expression, VEGFC may serve 
as a clinical marker to identify patients of increased risk for lymphatic metastases, a subpopulation that might benefit from VEGFC-specific treatment regimens (Kuerti et al., 2017).

\section{OVARIAN CANCER-ASSOCIATED EVS}

In the course of ovarian cancer progression, intercellular communication defines the pace of neoplastic cell survival and expansion. EVs are released by almost all cell types in the TME, and mediate the transfer of proteins, lipids, and nucleic acids (DNAs, mRNAs, miRNAs, and IncRNAs) between or within tumor and stroma (Han et al., 2017). EVs can be subdivided into exosomes (30-150 nm) and microvesicles $(100 \mathrm{~nm}-1 \mu \mathrm{m})$, depending on whether they are originated from multivesicular bodies (MVBs) or shed from the plasma membrane (Budnik et al., 2016). Stromareleased EVs can modulate the cancer cell invasion and metastasis, while cancer cells also generated EVs to induce functional transition of nearby stromal cells to favor disease progression. EV formation and release are regulated by multiple factors, while either endogenous or exogenous factors can change the number, content and type of EVs, thereby substantially altering their activities. For instance, biogenesis and release of cancer exosomes are regulated by endosomal sorting complex required for transport (ESCRT), intracellular calcium levels and structural scaffolding, and subject to stimulation by stresses such as microbial attacks (Azmi et al., 2013). Signal transduction via EVs adds another level of complexity to the cell communication network as EVs simultaneously release multiple molecules impinging on signaling pathways in the recipient cell.

As a subtype of non-coding RNAs, miRNAs control expression of target genes posttranscriptionally, while dysregulation of miRNAs is involved in multiple steps of ovarian cancer development. Exosomal miRNAs isolated from the serum or ascites have potential clinical values for ovarian cancer diagnosis, prognosis, and therapeutics (Nakamura et al., 2016). A former study reported the positivity of 218 out of 467 mature miRNAs isolated from ovarian cancer cells and exosomes of the same patients (Taylor and GercelTaylor, 2008). Among them, 8 specific miRNAs had similar levels between cellular and exosomal miRNAs and exhibited correlations in a range of $0.71-0.90$. Although EpCAM-positive exosomes were present in both patients with benign ovarian disease and those harboring ovarian cancer, exosomal miRNA from ovarian cancer patients displayed similar profiles and were considerably distinct from those observed in benign cases. Thus, miRNA profiling of circulating cancer exosomes can be potentially employed as a surrogate diagnostic marker for biopsy analysis (Taylor and GercelTaylor, 2008). The first study investigating the miRNAs in ovarian cancer tissues and cell lines found that miR-200a, miR-141, miR-200c, and miR-200b were most significantly overexpressed, while miR-199a, miR-140, miR-145, and
miR-125b1 were the most downregulated miRNAs (lorio et al., 2007). In addition, expression of miR-21, miR-203, and miR-205 whose levels were upregulated in ovarian cancer, were significantly elevated in OVCAR3 cells upon treatment by 5-aza-2'-deoxycytidine demethylating, suggesting DNA hypomethylation as a potential mechanism for miRNA overexpression (lorio et al., 2007). Particularly, the members of miR-200 family maintain epithelial cell integrity by suppression of EMT via direct inhibition of mesenchymal transcription factors zinc finger E-box-binding homeobox $1 / 2$ (ZEB1/ZEB2) and TGF- $\beta$, a potent inducer of EMT. Although downregulation of miR-200s in cancer cells promotes EMT and cancer metastasis, these molecules are highly expressed in ovarian cancer and cause metastasis primarily by enhancing cancer cell dissemination within the pelvic cavity (Choi and $\mathrm{Ng}, 2017$ ).

Increasing lines of evidence suggest that EVs in ovarian cancer ascites are associated with immune suppression, invasion, and treatment resistance (Worzfeld et al., 2017). Ovarian ascites-released EVs reduce the cytotoxicity of peripheral lymphocytes and promote apoptosis of DCs and lymphocytes (Yokoi et al., 2017). Further, EV-associated FAS-L purified from patient ascites triggers FAS-induced apoptosis in a $\mathrm{T}$ cell line, highlighting the possibility of elimination of FAS-bearing immune cells including $T$ cells by vesicle-delivered FAS-L, a process that allows immune evasion to support cancer cell survival (Abrahams et al., 2003). EVs from ovarian ascites can also inhibit $T$ cell activation by blocking the $T$ cell signaling cascade, an effect contributed by EV-associated phosphatidylserine (PS) (Kelleher et al., 2015). Depletion of $\mathrm{HSP}^{+} \mathrm{EVs}$ and blockade of HSP70/TLR2 interaction with A8, a specific peptide aptamer, can prevent the activation of MDSCs and abolish cancer progression in experimental mice, suggesting the potential of targeting EVs as a novel immunotherapy for ovarian cancer treatment (Gobbo et al., 2016)

Ovarian cancer-derived EVs carry molecules that directly regulate cancer cell migration, including CD24, EpCAM, and soluble activated leukocyte cell adhesion molecule (sALCAM) and soluble L1 (Carbotti et al., 2013; Gutwein et al., 2005; Runz et al., 2007). Malignant ascites-released membrane vesicles contain diverse activated proteases including MMP2, MMP9, UPA and ADAM17/TACE, together promoting ECM degradation and enhancing cancer cell invasiveness and metastasis (Carbotti et al., 2013; Graves et al., 2004). However, EVs may also carry miRNAs that positively or negatively regulate invasion and migration behaviors of cancer cells. For example, miR-6126 is released in a large amount via exosomes from both chemosensitive and chemoresistant ovarian cancer cells, and is correlated with longer overall survival in patients with HGSC (Kanlikilicer et al., 2016). Functionally targeting integrin $\beta 1$, a key regulator of cancer cell metastasis, miR-6126 acted as a tumor suppressor, and delivery of its mimic to endothelial cells (ECs) generates decreased ovarian cancer cell invasion and 
A

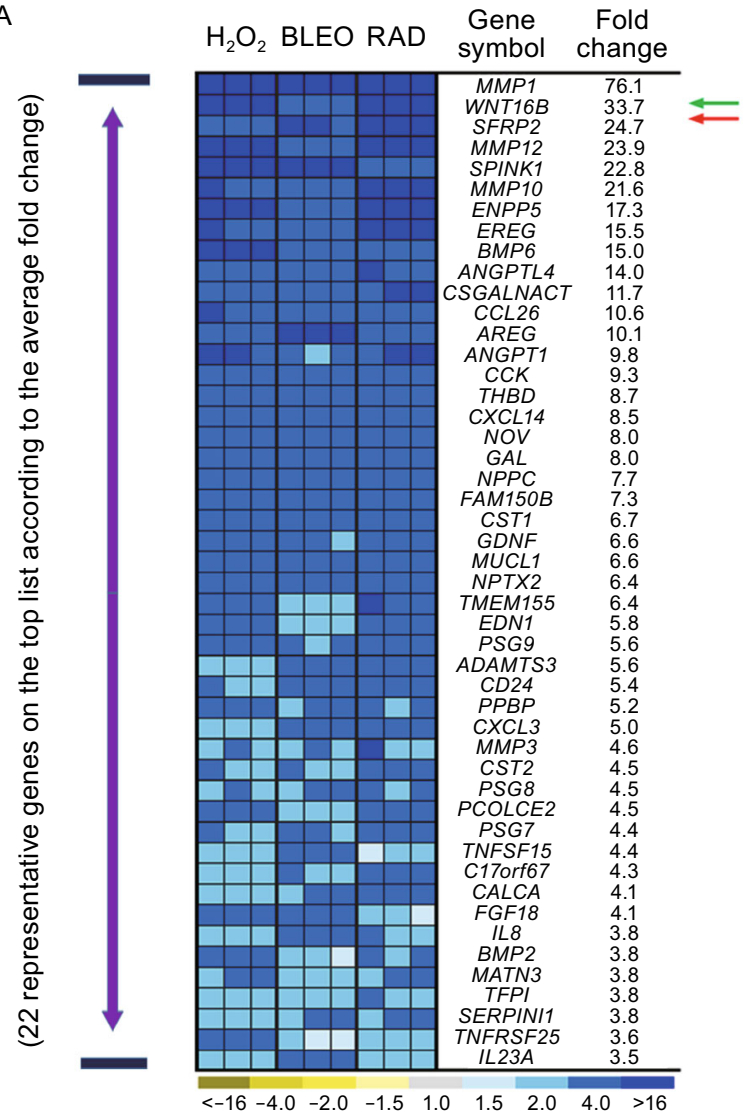

B

Disease exacerbation

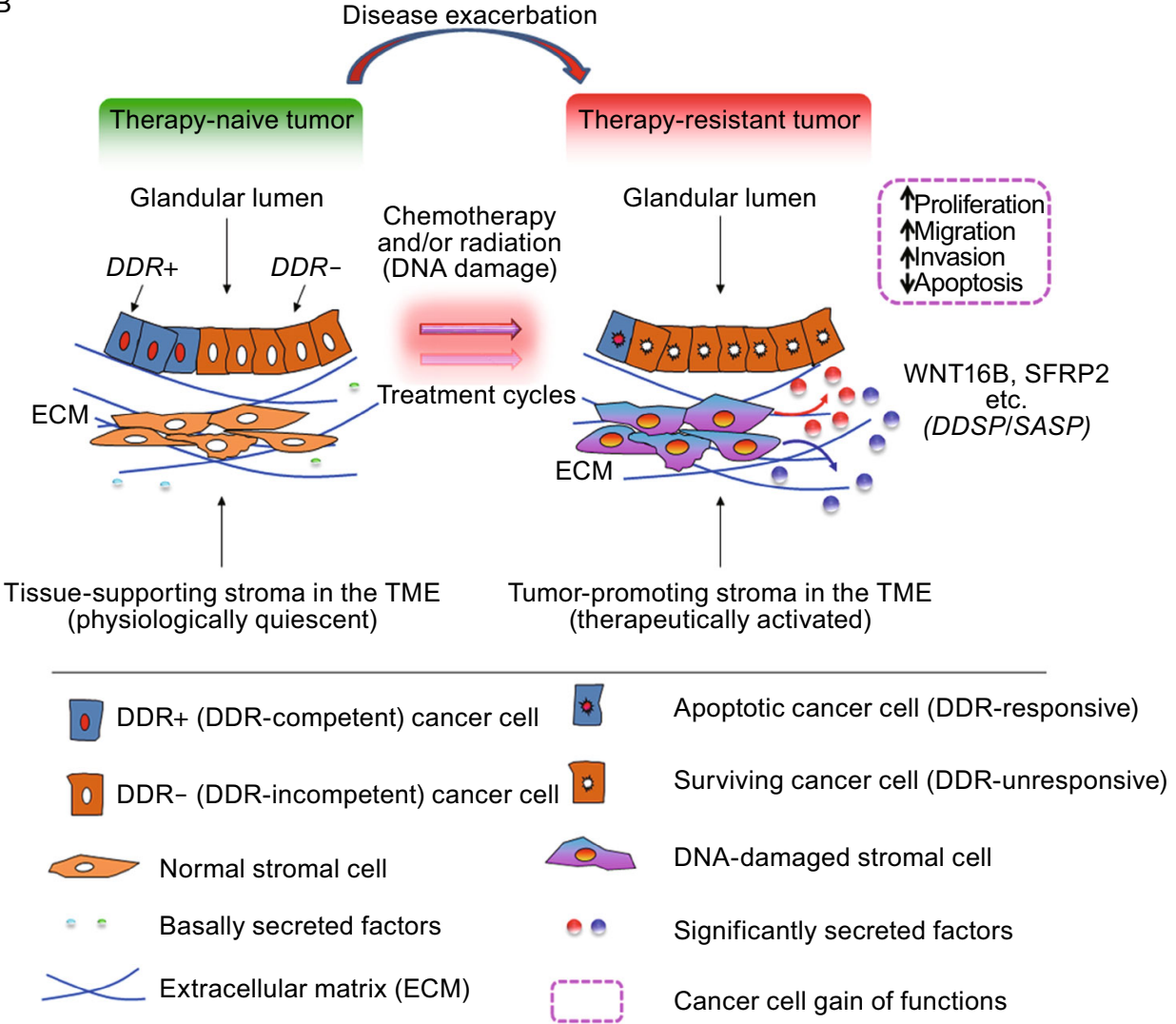


Figure 3. WNT16B and SFRP2 are significantly produced in human stromal cells during chemotherapy or radiation, and promote therapeutic resistance to surviving cancer cells. (A) Genome-wide expression pattern of primary normal human stromal cells. Heatmap depicts the relative mRNA abundance after exposure of cells to typical DNA damaging agents $\left(\mathrm{H}_{2} \mathrm{O}_{2}\right.$, hydrogen peroxide; Bleo, bleomycin; Rad, ionizing radiation). (B) Working model for cancer cell nonautonomous therapeutic resistance acquired from the TME upon anticancer treatments particularly genotoxic chemotherapy and radiation. Therapeutic agents cause apoptosis in subsets of cancer cells by eliciting a DDR, while cancer cells with DDR deficiency (DDR-insensitive, or DDR-) escape from cytotoxic attack. Simultaneously, senescence is induced in stromal cells adjacent to epithelial cells surrounding the gland, with a secretory phenotype DDSP developed after DDR events. A persistently activated signaling network is triggered by the DNA strand breaks. The DDSP is usually characterized by a spectrum of autocrine- and paracrine-acting proteins. The soluble factors reinforce the senescent phenotype in damaged cells, enhance cancer cell repopulation, with increased occurrence of tumor relapse and distant metastasis. As exemplified by the recently reported WNT16B, a handful of co-synthesized factors including SFRP2 hold the potential to serve as both a serum biomarker to determine treatment index, and a therapeutic target to minimize the TME-conferred therapeutic resistance. DDR, DNA damage response; ECM, extracellular matrix; TME, tumor microenvironment. Color images of $(\mathrm{A})$ adapted from Sun et al. with permission from Nature Medicine, copyright 2012.

migration in vitro as well as reduced tumor growth in vivo (Kanlikilicer et al., 2016).

Beyond above pathological effects, EV-associated miRNAs can remarkably change the response of recipient cells to various anticancer agents. EV-mediated miR21 transfer from stromal cells including omental CAAs and CAFs to ovarian cancer cells induces resistance to paclitaxel-based chemotherapy by directly targeting the mRNA of apoptotic peptidase activating factor 1 (APAF1), implying inhibition of the stromal-derived miR-21 transfer is an exploitable modality in management of metastatic and recurrent ovarian cancer patients (Au Yeung et al., 2016). A recent study revealed that acquired SMAD4 mutations increase the chemoresistance capacity of EOCs via a novel mechanism through which platinum-resistant cellderived SMAD4 ${ }^{+}$exosomes perpetuate an EMT phenotype and promote the expansion of platinum-refractory cell subpopulations (Crow et al., 2017). Stable miR-433 expression in A2780 ovarian cancer cells induces a cellular senescence phenotype characterized by typical morphological changes, phosphorylated retinoblastoma ( $p-R b)$ downregulation, and $\beta$-galactosidase activity enhancement (Weiner-Gorzel et al., 2015). Further, miR-433-expressing cancer cells release miR-433 into the growth media via exosomes which in turn can generate a senescence bystander effect, thus promoting the potential of recipient cells to survive chemotherapeutic treatment (Weiner-Gorzel et al., 2015). Exosomes released by a cisplatin-resistant derivative of A2780, CP70 cell line, were capable of driving resistance in treatment-naïve A2780 cells (Pink et al., 2015). Similarly, cisplatin-resistant SKOV3 cells can release increased numbers of exosomes, which contain detectable annexin $A 3$, a molecule correlated with platinum resistance of ovarian cancer cells (Yin et al., 2012).

\section{CONCLUDING REMARKS AND PROSPECTIVE VISTAS}

Decades of scientific and clinical efforts in ovarian cancer research provide an important baseline for the development of TME-oriented therapeutic agents that are mainly designed to interfere with tumor-stroma interactions in ovarian cancer patients. To date, many agents have achieved pronounced efficacy in improving patient survival when incorporated into traditional cytotoxic chemotherapies. However, like most human solid malignancies, ovarian cancer has distinct environmental landscapes and display substantial heterogeneity, even standardized treatments elicit a varying degree of responses among patient subgroups. To circumvent the difficulties, emerging new techniques provide substantial benefits for translational research. For instance, engineered nanochips such as Tantalum oxide nanodot arrays of 10-200 nm are now designed as artificial microenvironments, with the experimental setup and methodology specific for appraisal of ovarian cancer invasiveness (Dhawan et al., 2016). This technical advancement presents an optimal diagnostic platform to investigate cancer cell behavior, facilitate "markerless monitoring" of ovarian cancer progressiveness as a pilot model in the transdisciplinary fields of biomedical engineering and cancer research.

There has been a surge in clinical trials with drugs that specifically control transmembrane or cytoplasmic enzymes, induce apoptosis and suppress angiogenesis in site-specific ovarian cancer cells, thus holding considerable promise to design more efficacious protocols. Future exploration in this field should focus on how to improve the practical accuracy of current therapies, to identify an increasing number of ovary-specific molecular targets for optimal effectiveness, and to develop an omics-based system for patient stratification. Altogether, conceptual and technical advancement will allow physicians to make informed decisions in ovarian cancer clinics towards a thorough cure of this gynecological malignancy.

\section{ACKNOWLEDGEMENTS}

This review article is dedicated to Dr. Nelly Auersperg, a pioneer physician scientist who inspired the world to systematically investigate human ovarian cancer and continues to challenge our research in multiple fields. We are grateful to Drs. Peter Nelson and 
Judith Campisi for inspiring discussion and insightful comments. This work was supported by grants from National Key Research and Development Program of China (2016YFC1302400), National Natural Science Foundation of China (Grant Nos. 81472709 and 31671425), the National 1000 Young Talents Research Program of China, and the U.S. Department of Defense (DoD) Prostate Cancer Research Program (PCRP) (Idea Development Award PC111703) to Y.S.

\section{ABBREVIATIONS}

a-SMA, a-smooth muscle actin; AA, arachidonic acid; ANGPT1, angiopoietin 1; ANGPTL4, angiopoietin-like 4; APAF1, apoptotic peptidase activating factor 1; BMP, bone morphogenetic protein; CAA, cancer-associated adipocyte; CAF, cancer-associated fibroblast; CCL2, chemokine C-C motif ligand 2; CD::UPRT, cytosine deaminase::uracil phosphoribosyltransferase; CM, conditioned media; CSC, cancer stem cell; CSF1, colony stimulating factor 1; CXCR4, C-X-C chemokine receptor type 4; EC, endothelial cell; ECM, extracellular matrix; EMT, epithelial-mesenchymal transition; EOC, epithelial ovarian cancer; EpCAM, epithelial cell adhesion molecule; ER, estrogen receptor; ERK2, extracellular regulated kinase 2; ESCRT, endosomal sorting complex required for transport; EV, extracellular vesicle; FABP, fatty acid-binding protein; FAP, fibroblast activation protein; FGF, fibroblast growth factor; FRa, folate receptor; FXII, coagulation factor XII; 5-FC, 5-fluorocytosine; GCV, ganciclovir; GI tract, gastrointestinal tract; GPCR, G protein coupled receptor; GROa, growth regulated oncogene-a; HB-EGF, heparin-bound epidermal growth factor; HGF, hepatocyte growth factor; HGSC, high-grade serous carci-

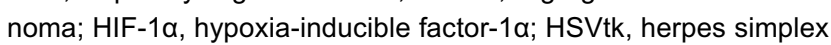
virus thymidine kinase; iDC, immature dendritic cells; IFNy, interferon gamma; IL, interleukin; LIF, leukemia inhibitory factor; IncRNA, long non-coding RNA; LPA, lysophosphatidic acids; LTB4, leukotriene B4; MDM, monocyte-derived macrophages; MDSC, myeloid derived suppressor cell; MIF, migration inhibitory factor; MMP, matrix metalloproteinase; MSC, mesenchymal stem cell; MVB, multivesicular bodies; NACT, neoadjuvant chemotherapy; NK, natural killer; NO, nitrous oxide; NOD-SCID, non-obese diabetic-severe combined immunodeficiency; O-ADSC, omental adipose-derived stem cell; PAI-1, plasminogen activator inhibitor-1; PAR1, protease-activated receptor-1; PGE2, prostaglandin E2; PGIR, prostaglandin I receptor; $\mathrm{PGI}_{2}$, prostaglandin I2; $\mathrm{PLA}_{2}$, phospholipase A2; PLA2G7, phospholipase A2 group VII; $\mathrm{PMPH}$, peritoneal macrophage; $\mathrm{p}-\mathrm{Rb}$, phosphorylated retinoblastoma; $\mathrm{PS}$, phosphatidylserine; PTGER3, prostaglandin E receptor 3; PTGIS, prostaglandin 12 synthase; PUFA, polyunsaturated fatty acids; ROS, reactive oxygen species; SDF-1, stromal cell-derived factor-1; SFRP2, secreted frizzled-related protein 2; SIK2, salt-inducible kinase 2; sALCAM, soluble activated leukocyte cell adhesion molecule; STAT3, signal transducer and activator of transcription3; TAM, tumor-associated macrophage; TIA-1, T cell intracellular antigen-1; TIL, tumor infiltrating lymphocyte; TIM, tumor infiltrating macrophage; TIMP1, tissue inhibitor of metalloproteinase 1; TGF- $\beta 1$, transforming growth factor $\beta 1$; TME, tumor microenvironment; TNF- $\alpha$, tumor necrosis factor alpha; TNFSF15, tumor necrosis factor superfamily-15; uPA, urokinase-type plasminogen activator;
VEGF, vascular endothelial growth factor; ZEB, zinc finger E-boxbinding homeobox.

\section{COMPLIANCE WITH ETHICS GUIDELINES}

Boyi Zhang, Fei Chen, Qixia Xu, Liu Han, Jiaqian Xu, Libin Gao, Xiaochen Sun, Yiwen Li, Yan Li, Min Qian, and Yu Sun declare that they have no conflict of interest. This article does not contain any studies with human or animal subjects performed by the any of the authors.

\section{OPEN ACCESS}

This article is distributed under the terms of the Creative Commons Attribution 4.0 International License (http://creativecommons.org/ licenses/by/4.0/), which permits unrestricted use, distribution, and reproduction in any medium, provided you give appropriate credit to the original author(s) and the source, provide a link to the Creative Commons license, and indicate if changes were made.

\section{REFERENCES}

Abrahams VM, Straszewski SL, Kamsteeg M, Hanczaruk B, Schwartz PE, Rutherford TJ, Mor G (2003) Epithelial ovarian cancer cells secrete functional Fas ligand. Cancer Res 63:55735581

Ackerman D, Simon MC (2014) Hypoxia, lipids, and cancer: surviving the harsh tumor microenvironment. Trends Cell Biol 24:472-478

Agarwal A, Tressel SL, Kaimal R, Balla M, Lam FH, Covic L, Kuliopulos A (2010) Identification of a metalloprotease-chemokine signaling system in the ovarian cancer microenvironment: implications for antiangiogenic therapy. Cancer Res 70:58805890

Aiello NM, Brabletz T, Kang Y, Nieto MA, Weinberg RA, Stanger BZ (2017) Upholding a role for EMT in pancreatic cancer metastasis. Nature 547:E7-E8

Alexander ET, Minton AR, Peters MC, van Ryn J, Gilmour SK (2016) Thrombin inhibition and cisplatin block tumor progression in ovarian cancer by alleviating the immunosuppressive microenvironment. Oncotarget 7:85291-85305

Allavena P, Signorelli M, Chieppa M, Erba E, Bianchi G, Marchesi F, Olimpio CO, Bonardi C, Garbi A, Lissoni A et al (2005) Antiinflammatory properties of the novel antitumor agent yondelis (Trabectedin): inhibition of macrophage differentiation and cytokine production. Cancer Res 65:2964-2971

Alvero AB, Montagna MK, Craveiro V, Liu LZ, Mor G (2012) Distinct subpopulations of epithelial ovarian cancer cells can differentially induce macrophages and T regulatory cells toward a pro-tumor phenotype. Am J Reprod Immunol 67:256-265

Au Yeung CL, Co NN, Tsuruga T, Yeung TL, Kwan SY, Leung CS, Li Y, Lu ES, Kwan K, Wong KK et al (2016) Exosomal transfer of stroma-derived miR21 confers paclitaxel resistance in ovarian cancer cells through targeting APAF1. Nat Commun 7:11150 
Augustin HG, Koh GY, Thurston G, Alitalo K (2009) Control of vascular morphogenesis and homeostasis through the angiopoietin-Tie system. Nat Rev Mol Cell Bio 10:165-177

Azmi AS, Bao B, Sarkar FH (2013) Exosomes in cancer development, metastasis, and drug resistance: a comprehensive review. Cancer Metastasis Rev 32:623-642

Blanco LZ, Kuhn E, Morrison JC, Bahadirli-Talbott A, Smith-Sehdev A, Kurman RJ (2017) Steroid hormone synthesis by the ovarian stroma surrounding epithelial ovarian tumors: a potential mechanism in ovarian tumorigenesis. Mod Pathol 30:563-576

Bohm S, Montfort A, Pearce OMT, Topping J, Chakravarty P, Everitt GLA, Clear A, McDermott JR, Ennis D, Dowe T et al (2016) Neoadjuvant chemotherapy modulates the immune microenvironment in metastases of tubo-ovarian high-grade serous carcinoma. Clin Cancer Res 22:3025-3036

Bravo-Sagua, R., Mattar, P., Diaz, X., Lavandero, S., Cifuentes, M. (2016). Calcium sensing receptor as a novel mediator of adipose tissue dysfunction: mechanisms and potential clinical implications. Front Physiol 7.

Brunckhorst MK, Xu Y, Lu R, Yu Q (2014) Angiopoietins promote ovarian cancer progression by establishing a procancer microenvironment. Am J Pathol 184:2285-2296

Budnik V, Ruiz-Canada C, Wendler F (2016) Extracellular vesicles round off communication in the nervous system. Nat Rev Neurosci 17:160-172

Bussard KM, Mutkus L, Stumpf K, Gomez-Manzano C, Marini FC (2016) Tumor-associated stromal cells as key contributors to the tumor microenvironment. Breast Cancer Res 18:84

Cai J, Tang H, Xu L, Wang X, Yang C, Ruan S, Guo J, Hu S, Wang Z (2012) Fibroblasts in omentum activated by tumor cells promote ovarian cancer growth, adhesion and invasiveness. Carcinogenesis 33:20-29

Carbotti G, Orengo AM, Mezzanzanica D, Bagnoli M, Brizzolara A, Emionite L, Puppo A, Centurioni MG, Bruzzone M, Marroni P et al (2013) Activated leukocyte cell adhesion molecule soluble form: a potential biomarker of epithelial ovarian cancer is increased in type II tumors. Int J Cancer 132:2597-2605

Cardenas C, Montagna MK, Pitruzzello M, Lima E, Mor G, Alvero AB (2017) Adipocyte microenvironment promotes $\mathrm{Bcl}(\mathrm{xl})$ expression and confers chemoresistance in ovarian cancer cells. Apoptosis 22:558-569

Carroll MJ, Kapur A, Felder M, Patankar MS, Kreeger PK (2016) M2 macrophages induce ovarian cancer cell proliferation via a heparin binding epidermal growth factor/matrix metalloproteinase 9 intercellular feedback loop. Oncotarget 7:86608-86620

Chang DK, Peterson E, Sun J, Goudie C, Drapkin RI, Liu JF, Matulonis U, Zhu Q, Marasco WA (2016) Anti-CCR4 monoclonal antibody enhances antitumor immunity by modulating tumorinfiltrating Tregs in an ovarian cancer xenograft humanized mouse model. Oncoimmunology 5:e1090075

Chen F, Zhuang X, Lin L, Yu P, Wang Y, Shi Y, Hu G, Sun Y (2015) New horizons in tumor microenvironment biology: challenges and opportunities. BMC Med 13:278

Chen, X., Ying, X., Wang, X., Wu, X., Zhu, Q., and Wang, X. (2017). Exosomes derived from hypoxic epithelial ovarian cancer deliver microRNA-940 to induce macrophage M2 polarization. Oncol Rep.
Cho JA, Park H, Lim EH, Kim KH, Choi JS, Lee JH, Shin JW, Lee KW (2011) Exosomes from ovarian cancer cells induce adipose tissue-derived mesenchymal stem cells to acquire the physical and functional characteristics of tumor-supporting myofibroblasts. Gynecol Oncol 123:379-386

Choi PW, Ng SW (2017) The functions of MicroRNA-200 family in ovarian cancer: beyond epithelial-mesenchymal transition. Int J Mol Sci 18:1207

Choi JH, Lee KT, Leung PCK (2011) Estrogen receptor alpha pathway is involved in leptin-induced ovarian cancer cell growth. Carcinogenesis 32:589-596

Clark R, Krishnan V, Schoof M, Rodriguez I, Theriault B, Chekmareva M, Rinker-Schaeffert C (2013) Milky spots promote ovarian cancer metastatic colonization of peritoneal adipose in experimental models. Am J Pathol 183:576-591

Coffelt SB, Marini FC, Watson K, Zwezdaryk KJ, Dembinski JL, LaMarca HL, Tomchuck SL, Honer zu Bentrup K, Danka ES, Henkle SL, Scandurro AB (2009) The pro-inflammatory peptide LL-37 promotes ovarian tumor progression through recruitment of multipotent mesenchymal stromal cells. Proc Natl Acad Sci USA 106:3806-3811

Condamine T, Ramachandran I, Youn JI, Gabrilovich DI (2015) Regulation of tumor metastasis by myeloid-derived suppressor cells. Annu Rev Med 66:97-110

Coppe JP, Patil CK, Rodier F, Sun Y, Munoz DP, Goldstein J, Nelson PS, Desprez PY, Campisi J (2008) Senescence-associated secretory phenotypes reveal cell-nonautonomous functions of oncogenic RAS and the p53 tumor suppressor. PLoS Biol 6:2853-2868

Courtwright A, Siamakpour-Reihani S, Arbiser JL, Banet N, Hilliard E, Fried L, Livasy C, Ketelsen D, Nepal DB, Perou CM et al (2009) Secreted frizzle-related protein 2 stimulates angiogenesis via a calcineurin/NFAT signaling pathway. Cancer Res 69:46214628

Crow J, Atay S, Banskota S, Artale B, Schmitt S, Godwin AK (2017) Exosomes as mediators of platinum resistance in ovarian cancer. Oncotarget 8:11917-11936

Curiel TJ, Coukos G, Zou L, Alvarez X, Cheng P, Mottram P, Evdemon-Hogan M, Conejo-Garcia JR, Zhang L, Burow $M$ et al (2004) Specific recruitment of regulatory $T$ cells in ovarian carcinoma fosters immune privilege and predicts reduced survival. Nat Med 10:942-949

da Silva RF, Yoshida A, Cardozo DM, Jales RM, Paust S, Derchain S, Guimarães F (2017) Natural killer cells response to IL-2 stimulation is distinct between ascites with the presence or absence of malignant cells in ovarian cancer patients. Int $\mathrm{J} \mathrm{Mol}$ Sci 18:E856

Deng WM, Gu X, Lu Y, Gu C, Zheng YY, Zhang ZS, Chen L, Yao Z, Li LY (2012) Down-modulation of TNFSF15 in ovarian cancer by VEGF and MCP-1 is a pre-requisite for tumor neovascularization. Angiogenesis 15:71-85

Dhawan U, Wang SM, Chu YH, Huang GS, Lin YR, Hung YC, Chen WL (2016) Nanochips of tantalum oxide nanodots as artificialmicroenvironments for monitoring Ovarian cancer progressiveness. Sci Rep 6:31998

Ding DC, Liu HW, Chu TY (2016) Interleukin-6 from ovarian mesenchymal stem cells promotes proliferation, sphere and 
colony formation and tumorigenesis of an ovarian cancer cell line SKOV3. J Cancer 7:1815-1823

Dirat B, Bochet L, Dabek M, Daviaud D, Dauvillier S, Majed B, Wang YY, Meulle A, Salles B, Le Gonidec S et al (2011) Cancerassociated adipocytes exhibit an activated phenotype and contribute to breast cancer invasion. Cancer Res 71:2455-2465

Duluc D, Delneste Y, Tan F, Moles MP, Grimaud L, Lenoir J, Preisser L, Anegon I, Catala L, Ifrah N et al (2007) Tumor-associated leukemia inhibitory factor and IL-6 skew monocyte differentiation into tumor-associated macrophage-like cells. Blood 110:43194330

Duluc D, Corvaisier M, Blanchard S, Catala L, Descamps P, Gamelin E, Ponsoda S, Delneste Y, Hebbar M, Jeannin P (2009) Interferon-gamma reverses the immunosuppressive and protumoral properties and prevents the generation of human tumorassociated macrophages. Int J Cancer 125:367-373

Felices M, Chu S, Kodal B, Bendzick L, Ryan C, Lenvik AJ, Boylan KLM, Wong HC, Skubitz APN, Miller JS, Geller MA (2017) IL-15 super-agonist (ALT-803) enhances natural killer (NK) cell function against ovarian cancer. Gynecol Oncol 145:453-461

Finkernagel F, Reinartz S, Lieber S, Adhikary T, Wortmann A, Hoffmann N, Bieringer T, Nist A, Stiewe T, Jansen JM et al (2016) The transcriptional signature of human ovarian carcinoma macrophages is associated with extracellular matrix reorganization. Oncotarget 7:75339-75352

Geis AL, Fan H, Wu X, Wu S, Huso DL, Wolfe JL, Sears CL, Pardoll DM, Housseau F (2015) Regulatory T-cell response to enterotoxigenic Bacteroides fragilis colonization triggers IL17-dependent colon carcinogenesis. Cancer Dis 5:1098-1109

Gobbo, J., Marcion, G., Cordonnier, M., Dias, A. M. M., Pernet, N., Hammann, A., Richaud, S., Mjahed, H., Isambert, N., Clausse, V., et al. (2016). Restoring Anticancer Immune Response by Targeting Tumor-Derived Exosomes With a HSP70 Peptide Aptamer. J Natl Cancer Inst 108.

Graves LE, Ariztia EV, Navari JR, Matzel HJ, Stack MS, Fishman DA (2004) Proinvasive properties of ovarian cancer ascites-derived membrane vesicles. Cancer Res 64:7045-7049

Guaita-Esteruelas, S., Guma, J., Masana, L., and Borras, J. (2017). The peritumoural adipose tissue microenvironment and cancer. The roles of fatty acid binding protein 4 and fatty acid binding protein 5. Mol Cell Endocrinol.

Gusky HC, Diedrich J, MacDougald OA, Podgorski I (2016) Omentum and bone marrow: how adipocyte-rich organs create tumour microenvironments conducive for metastatic progression. Obes Rev 17:1015-1029

Gutwein P, Stoeck A, Riedle S, Gast D, Runz S, Condon TP, Marme A, Phong MC, Linderkamp O, Skorokhod A, Altevogt P (2005) Cleavage of $L 1$ in exosomes and apoptotic membrane vesicles released from ovarian carcinoma cells. Clin Cancer Res 11:2492-2501

Hagemann T, Wilson J, Burke F, Kulbe H, Li NF, Pluddemann A, Charles K, Gordon S, Balkwill FR (2006) Ovarian cancer cells polarize macrophages toward a tumor-associated phenotype. $J$ Immunol 176:5023-5032

Han L, Xu J, Xu Q, Zhang B, Lam EW, Sun Y (2017). Extracellular vesicles in the tumor microenvironment: Therapeutic resistance, clinical biomarkers, and targeting strategies. Med Res Rev.
Hanahan D, Weinberg RA (2011) Hallmarks of cancer: the next generation. Cell 144:646-674

Harjes U, Bridges E, Gharpure KM, Roxanis I, Sheldon H, Miranda F, Mangala LS, Pradeep S, Lopez-Berestein G, Ahmed A et al (2017) Antiangiogenic and tumour inhibitory effects of downregulating tumour endothelial FABP4. Oncogene 36:912-921

Hart KM, Byrne KT, Molloy MJ, Usherwood EM, Berwin B (2011) IL10 immunomodulation of myeloid cells regulates a murine model of ovarian cancer. Front Immunol 2:29

Heindl A, Lan C, Rodrigues DN, Koelble K, Yuan Y (2016) Similarity and diversity of the tumor microenvironment in multiple metastases: critical implications for overall and progression-free survival of high-grade serous ovarian cancer. Oncotarget 7:71123-71135

Hu W, Wang J, He X, Zhang H, Yu F, Jiang L, Chen D, Chen J, Dou J (2011) Human umbilical blood mononuclear cell-derived mesenchymal stem cells serve as interleukin-21 gene delivery vehicles for epithelial ovarian cancer therapy in nude mice. Biotechnol Appl Biochem 58:397-404

Huang S, Van Arsdall M, Tedjarati S, McCarty M, Wu W, Langley R, Fidler IJ (2002) Contributions of stromal metalloproteinase-9 to angiogenesis and growth of human ovarian carcinoma in mice. J Natl Cancer Inst 94:1134-1142

Huijbers EJM, van Beijnum JR, Thijssen VL, Sabrkhany S, NowakSliwinska P, Griffioen AW (2016) Role of the tumor stroma in resistance to anti-angiogenic therapy. Drug Resist Update 25:26-37

lorio MV, Visone R, Di Leva G, Donati V, Petrocca F, Casalini P, Taccioli C, Volinia S, Liu CG, Alder H et al (2007) MicroRNA signatures in human ovarian cancer. Cancer Res 67:8699-8707

Jiang J, Chen W, Zhuang R, Song T, Li P (2010) The effect of endostatin mediated by human mesenchymal stem cells on ovarian cancer cells in vitro. J Cancer Res Clin Oncol 136:873881

Josephs DH, Bax HJ, Dodev T, Georgouli M, Nakamura M, Pellizzari G, Saul L, Karagiannis P, Cheung A, Herraiz C et al (2017) Antifolate receptor-alpha $\lg E$ but not $\lg G$ recruits macrophages to attack tumors via TNFalpha/MCP-1 signaling. Cancer Res 77:1127-1141

Kanlikilicer P, Rashed MH, Bayraktar R, Mitra R, Ivan C, Aslan B, Zhang X, Filant J, Silva AM, Rodriguez-Aguayo C et al (2016) Ubiquitous release of exosomal tumor suppressor miR-6126 from ovarian cancer cells. Cancer Res 76:7194-7207

Karnezis AN, Cho KR, Gilks CB, Pearce CL, Huntsman DG (2017) The disparate origins of ovarian cancers: pathogenesis and prevention strategies. Nat Rev Cancer 17:65-74

Ke X, Zhang S, Wu M, Lou J, Zhang J, Xu T, Huang L, Huang P, Wang F, Pan S (2016) Tumor-associated macrophages promote invasion via Toll-like receptors signaling in patients with ovarian cancer. Int Immunopharmacol 40:184-195

Kelleher RJ Jr, Balu-lyer S, Loyall J, Sacca AJ, Shenoy GN, Peng P, lyer V, Fathallah AM, Berenson CS, Wallace PK et al (2015) Extracellular vesicles present in human ovarian tumor microenvironments induce a phosphatidylserine-dependent arrest in the T-cell signaling cascade. Cancer Immunol Res 3:1269-1278

Kipps E, Tan DS, Kaye SB (2013) Meeting the challenge of ascites in ovarian cancer: new avenues for therapy and research. Nat Rev Cancer 13:273-282 
Klemm F, Joyce JA (2015) Microenvironmental regulation of therapeutic response in cancer. Trends Cell Biol 25:198-213

Kobayashi H, Iwai K, Niiro E, Morioka S, Yamada Y, Ogawa K, Kawahara N (2017) The conceptual advances of carcinogenic sequence model in high-grade serous ovarian cancer. Biomed Rep 7:209-213

Komdeur FL, Wouters MCA, Workel HH, Tijans AM, Terwindt ALJ, Brunekreeft KL, Plat A, Klip HG, Eggink FA, Leffers N et al (2016) CD103+intraepithelial T cells in high-grade serous ovarian cancer are phenotypically diverse TCR alpha beta+CD8 alpha beta plus $T$ cells that can be targeted for cancer immunotherapy. Oncotarget 7:75130-75144

Kraman M, Bambrough PJ, Arnold JN, Roberts EW, Magiera L, Jones JO, Gopinathan A, Tuveson DA, Fearon DT (2010) Suppression of antitumor immunity by stromal cells expressing fibroblast activation protein-alpha. Science 330:827-830

Krockenberger M, Dombrowski Y, Weidler C, Ossadnik M, Honig A, Hausler S, Voigt H, Becker JC, Leng L, Steinle A et al (2008) Macrophage migration inhibitory factor contributes to the immune escape of ovarian cancer by down-regulating NKG2D. J Immunol 180:7338-7348

Kuerti S, Oliveira-Ferrer L, Milde-Langosch K, Schmalfeldt B, Legler K, Woelber L, Prieske K, Mahner S, Trillsch F (2017) VEGF-C expression attributes the risk for lymphatic metastases to ovarian cancer patients. Oncotarget 8:43218

Labiche A, Heutte N, Herlin P, Chasle J, Gauduchon P, Elie N (2010) Stromal compartment as a survival prognostic factor in advanced ovarian carcinoma. Int J Gynecol Cancer 20:28-33

Landskron J, Helland O, Torgersen KM, Aandahl EM, Gjertsen BT, Bjorge L, Tasken K (2015) Activated regulatory and memory T-cells accumulate in malignant ascites from ovarian carcinoma patients. Cancer Immunol Immunother 64:337-347

Latifi A, Abubaker K, Castrechini N, Ward AC, Liongue C, Dobill F, Kumar J, Thompson EW, Quinn MA, Findlay JK, Ahmed N (2011) Cisplatin treatment of primary and metastatic epithelial ovarian carcinomas generates residual cells with mesenchymal stem celllike profile. J Cell Biochem 112:2850-2864

Lengyel E (2010) Ovarian cancer development and metastasis. Am J Pathol 177:1053-1064

Linnerth-Petrik NM, Santry LA, Moorehead R, Jucker M, Wootton SK, Petrik J (2016) Akt isoform specific effects in ovarian cancer progression. Oncotarget 7:74820-74833

Liu YY, Metzinger MN, Lewellen KA, Cripps SN, Carey KD, Harper El, Shi ZG, Tarwater L, Grisoli A, Lee E et al (2015) Obesity contributes to ovarian cancer metastatic success through increased lipogenesis, enhanced vascularity, and decreased infiltration of M1 macrophages. Cancer Res 75:5046-5057

Lu X, Horner JW, Paul E, Shang X, Troncoso P, Deng P, Jiang S, Chang Q, Spring DJ, Sharma P et al (2017) Effective combinatorial immunotherapy for castration-resistant prostate cancer. Nature 543:728-732

Martinet L, Poupot R, Mirshahi P, Rafii A, Fournie JJ, Mirshahi M, Poupot M (2010) Hospicells derived from ovarian cancer stroma inhibit T-cell immune responses. Int J Cancer 126:2143-2152

McDaniel AS, Stall JN, Hovelson DH, Cani AK, Liu CJ, Tomlins SA, Cho KR (2015) Next-generation sequencing of tubal intraepithelial carcinomas. JAMA Oncol 1:1128-1132
McLean K, Gong Y, Choi Y, Deng N, Yang K, Bai S, Cabrera L, Keller E, McCauley L, Cho KR, Buckanovich RJ (2011) Human ovarian carcinoma-associated mesenchymal stem cells regulate cancer stem cells and tumorigenesis via altered BMP production. J Clin Investig 121:3206-3219

Mikula-Pietrasik J, Uruski P, Sosinska P, Maksin K, PiotrowskaKempisty H, Kucinska M, Murias M, Szubert S, Wozniak A, Szpurek D et al (2016) Senescent peritoneal mesothelium creates a niche for ovarian cancer metastases. Cell Death Dis 7:e2565

Milne K, Kobel M, Kalloger SE, Barnes RO, Gao D, Gilks CB, Watson $\mathrm{PH}$, Nelson $\mathrm{BH}$ (2009) Systematic analysis of immune infiltrates in high-grade serous ovarian cancer reveals CD20, FoxP3 and TIA-1 as positive prognostic factors. PLos ONE 4:e6412

Miranda F, Ahmed AA (2017) How to make ovarian cancer cells "sick-too". Cell Cycle 16:15-16

Miranda F, Mannion D, Liu S, Zheng Y, Mangala LS, Redondo C, Herrero-Gonzalez S, Xu R, Taylor C, Chedom DF et al (2016) Salt-inducible Kinase 2 couples ovarian cancer cell metabolism with survival at the adipocyte-rich metastatic niche. Cancer Cell 30:273-289

Mukherjee S, Pal M, Mukhopadhyay S, Das I, Hazra R, Ghosh S, Mondal RK, Bal R (2017). VEGF expression to support targeted therapy in ovarian surface epithelial neoplasms. J Clin Diagn Res 11: EC43-EC46.

Musrap N, Diamandis EP (2012) Revisiting the complexity of the ovarian cancer microenvironment-clinical implications for treatment strategies. Mol Cancer Res 10:1254-1264

Nakamura K, Sawada K, Yoshimura A, Kinose Y, Nakatsuka E, Kimura T (2016) Clinical relevance of circulating cell-free microRNAs in ovarian cancer. Mol Cancer 15:48

Nieman KM, Kenny HA, Penicka CV, Ladanyi A, Buell-Gutbrod R, Zillhardt MR, Romero IL, Carey MS, Mills GB, Hotamisligil GS et al (2011) Adipocytes promote ovarian cancer metastasis and provide energy for rapid tumor growth. Nat Med 17:1498-1503

Nieman KM, Romero IL, Van Houten B, Lengyel E (2013) Adipose tissue and adipocytes support tumorigenesis and metastasis. Biochim Biophys Acta 1831:1533-1541

Noskova V, Ahmadi S, Asander E, Casslen B (2009) Ovarian cancer cells stimulate uPA gene expression in fibroblastic stromal cells via multiple paracrine and autocrine mechanisms. Gynecol Oncol 115:121-126

Obermajer N, Muthuswamy R, Odunsi K, Edwards RP, Kalinski P (2011) PGE(2)-induced CXCL12 production and CXCR4 expression controls the accumulation of human MDSCs in ovarian cancer environment. Cancer Res 71:7463-7470

Olive KP, Jacobetz MA, Davidson CJ, Gopinathan A, Mclntyre D, Honess D, Madhu B, Goldgraben MA, Caldwell ME, Allard D et al (2009) Inhibition of Hedgehog signaling enhances delivery of chemotherapy in a mouse model of pancreatic cancer. Science 324:1457-1461

Pesce S, Tabellini G, Cantoni C, Patrizi O, Coltrini D, Rampinelli F, Matta J, Vivier E, Moretta A, Parolini S, Marcenaro E (2015) B7H6-mediated downregulation of NKp30 in NK cells contributes to ovarian carcinoma immune escape. Oncoimmunology 4: e1001224 
Pink RC, Samuel P, Massa D, Caley DP, Brooks SA, Carter DRF (2015) The passenger strand, miR-21-3p, plays a role in mediating cisplatin resistance in ovarian cancer cells. Gynecol Oncol 137:143-151

Pogge von Strandmann E, Reinartz S, Wager U, Müller R (2017) Tumor-host cell interactions in ovarian cancer: pathways to therapy failure. Trends Cancer 3:137-148

Rabban JT, Vohra P, Zaloudek CJ (2015) Nongynecologic metastases to fallopian tube mucosa: a potential mimic of tubal highgrade serous carcinoma and benign tubal mucinous metaplasia or nonmucinous hyperplasia. Am J Surg Pathol 39:35-51

Reinartz S, Finkernagel F, Adhikary T, Rohnalter V, Schumann T, Schober Y, Nockher WA, Nist A, Stiewe T, Jansen JM et al (2016) A transcriptome-based global map of signaling pathways in the ovarian cancer microenvironment associated with clinical outcome. Genome Biol 17:108

Runz S, Keller S, Rupp C, Stoeck A, Issa Y, Koensgen D, Mustea A, Sehouli J, Kristiansen G, Altevogt $P$ (2007) Malignant ascitesderived exosomes of ovarian carcinoma patients contain CD24 and EpCAM. Gynecol Oncol 107:563-571

Saharinen P, Eklund L, Pulkki K, Bono P, Alitalo K (2011) VEGF and angiopoietin signaling in tumor angiogenesis and metastasis. Trends Mol Med 17:347-362

Sato E, Olson SH, Ahn J, Bundy B, Nishikawa H, Qian F, Jungbluth AA, Frosina D, Gnjatic S, Ambrosone $C$ et al (2005a) Intraepithelial CD8(+) tumor-infiltrating lymphocytes and a high CD8(+)/ regulatory $T$ cell ratio are associated with favorable prognosis in ovarian cancer. Proc Natl Acad Sci USA 102:18538-18543

Sato E, Olson SH, Ahn J, Bundy B, Nishikawa H, Qian F, Jungbluth AA, Frosina D, Gnjatic S, Ambrosone $C$ et al (2005b) Intraepithelial CD8+ tumor-infiltrating lymphocytes and a high CD8+/ regulatory $\mathrm{T}$ cell ratio are associated with favorable prognosis in ovarian cancer. Proc Natl Acad Sci USA 102:18538-18543

Schauer IG, Sood AK, Mok S, Liu JS (2011) Cancer-associated fibroblasts and their putative role in potentiating the initiation and development of epithelial ovarian cancer. Neoplasia 13:393-405

Schmidt BA, Horsley V (2013) Intradermal adipocytes mediate fibroblast recruitment during skin wound healing. Development 140:1517-1527

Scully RE, Richardson GS (1961) Luteinization of the stroma of metastatic cancer involving the ovary and its endocrine significance. Cancer 14:827-840

Sheng X, Mittelman SD (2014) The role of adipose tissue and obesity in causing treatment resistance of acute lymphoblastic leukemia. Frontiers Pediatr 2:53

Siamakpour-Reihani S, Caster J, Bandhu Nepal D, Courtwright A, Hilliard E, Usary J, Ketelsen D, Darr D, Shen XJ, Patterson C, Klauber-Demore N (2011) The role of calcineurin/NFAT in SFRP2 induced angiogenesis-a rationale for breast cancer treatment with the calcineurin inhibitor tacrolimus. PLos ONE 6:e20412

Simpson S (2007) Trabectedin too toxic in ovarian cancer? Lancet Oncol 8:1061

Spaeth EL, Dembinski JL, Sasser AK, Watson K, Klopp A, Hall B, Andreeff M, Marini F (2009) Mesenchymal stem cell transition to tumor-associated fibroblasts contributes to fibrovascular network expansion and tumor progression. PLos ONE 4:e4992
Straussman R, Morikawa T, Shee K, Barzily-Rokni M, Qian ZR, Du JY, Davis A, Mongare MM, Gould J, Frederick DT et al (2012) Tumour micro-environment elicits innate resistance to RAF inhibitors through HGF secretion. Nature 487:500-504

Sun $Y$ (2015) Translational horizons in the tumor microenvironment: harnessing breakthroughs and targeting cures. Med Res Rev 35:408-436

Sun Y, Campisi J, Higano C, Beer TM, Porter P, Coleman I, True L, Nelson PS (2012) Treatment-induced damage to the tumor microenvironment promotes prostate cancer therapy resistance through WNT16B. Nat Med 18:1359-1368

Sun Y, Zhu D, Chen F, Qian M, Wei H, Chen W, Xu J (2016) SFRP2 augments WNT16B signaling to promote therapeutic resistance in the damaged tumor microenvironment. Oncogene 35:43214334

Tajan M, Vousden KH (2016) The quid pro quo of the tumor/stromal interaction. Cell Metab 24:645-646

Taylor DD, Gercel-Taylor C (2008) MicroRNA signatures of tumorderived exosomes as diagnostic biomarkers of ovarian cancer. Gynecol Oncol 110:13-21

Tchkonia T, Morbeck DE, Von Zglinicki T, Van Deursen J, Lustgarten J, Scrable H, Khosla S, Jensen MD, Kirkland JL (2010) Fat tissue, aging, and cellular senescence. Aging Cell 9:667-684

Toro L, Bohovic R, Matuskova M, Smolkova B, Kucerova L (2016) Metastatic ovarian cancer can be efficiently treated by genetically modified mesenchymal stromal cells. Stem Cells Dev 25:16401651

Tucker SL, Gharpure K, Herbrich SM, Unruh AK, Nick AM, Crane EK, Coleman RL, Guenthoer J, Dalton HJ, Wu SY et al (2014) Molecular biomarkers of residual disease after surgical debulking of high-grade serous ovarian cancer. Clin Cancer Res 20:32803288

Walter M, Liang S, Ghosh S, Hornsby PJ, Li R (2009) Interleukin 6 secreted from adipose stromal cells promotes migration and invasion of breast cancer cells. Oncogene 28:2745-2755

Wang R, Zhang T, Ma Z, Wang Y, Cheng Z, Xu H, Li W, Wang X (2010) The interaction of coagulation factor XII and monocyte/macrophages mediating peritoneal metastasis of epithelial ovarian cancer. Gynecol Oncol 117:460-466

Wang WM, Kryczek I, Dostal L, Lin H, Tan LJ, Zhao LL, Lu FJ, Wei S, Maj T, Peng DJ et al (2016) Effector T cells abrogate stromamediated chemoresistance in ovarian cancer. Cell 165:10921105

Webb JR, Milne K, Watson P, deLeeuw RJ, Nelson BH (2014) Tumor-infiltrating lymphocytes expressing the tissue resident memory marker CD103 are associated with increased survival in high-grade serous ovarian cancer. Clin Cancer Res 20:434-444

Weiner-Gorzel K, Dempsey E, Milewska M, McGoldrick A, Toh V, Walsh A, Lindsay S, Gubbins L, Cannon A, Sharpe D et al (2015) Overexpression of the microRNA miR-433 promotes resistance to paclitaxel through the induction of cellular senescence in ovarian cancer cells. Cancer Med-Us 4:745-758

Wilson TR, Fridlyand J, Yan YB, Penuel E, Burton L, Chan E, Peng J, Lin E, Wang YL, Sosman J et al (2012) Widespread potential for growth-factor-driven resistance to anticancer kinase inhibitors. Nature 487:505-u1652 
Wong JL, Berk E, Edwards RP, Kalinski P (2013) IL-18-primed helper NK cells collaborate with dendritic cells to promote recruitment of effector CD8+ T cells to the tumor microenvironment. Cancer Res 73:4653-4662

Worzfeld T, Pogge von Strandmann E, Huber M, Adhikary T, Wagner U, Reinartz S, Muller R (2017) The unique molecular and cellular microenvironment of ovarian cancer. Front Oncol 7:24

Wu M, Chen X, Lou JF, Zhang SP, Zhang XJ, Huang L, Sun RH, Huang PJ, Wang F, Pan SY (2016a) TGF-beta 1 contributes to CD8(+) Treg induction through p38 MAPK signaling in ovarian cancer microenvironment. Oncotarget 7:44534-44544

Wu M, Lou J, Zhang S, Chen X, Huang L, Sun R, Huang P, Pan S, Wang $F(2016 b)$ Gene expression profiling of CD8+ T cells induced by ovarian cancer cells suggests a possible mechanism for CD8+ Treg cell production. Cell Prolif 49:669-677

Wu M, Chen X, Lou J, Zhang S, Zhang X, Huang L, Sun R, Huang P, Pan S, Wang $F(2017 a)$ Changes in regulatory T cells in patients with ovarian cancer undergoing surgery: preliminary results. Int Immunopharmacol 47:244-250

Wu Q, Wu X, Ying X, Zhu Q, Wang X, Jiang L, Chen X, Wu Y, Wang $X$ (2017b) Suppression of endothelial cell migration by tumor associated macrophage-derived exosomes is reversed by epithelial ovarian cancer exosomal IncRNA. Cancer Cell Int 17:62

Yang L, Achreja A, Yeung TL, Mangala LS, Jiang D, Han C, Baddour J, Marini JC, Ni J, Nakahara R et al (2016) Targeting stromal glutamine synthetase in tumors disrupts tumor microenvironment-regulated cancer cell growth. Cell Metab 24:685-700

Yin J, Yan XD, Yao X, Zhang YL, Shan Y, Mao N, Yang YL, Pan LY (2012) Secretion of annexin A3 from ovarian cancer cells and its association with platinum resistance in ovarian cancer patients. J Cell Mol Med 16:337-348

Yokoi A, Yoshioka Y, Yamamoto Y, Ishikawa M, Ikeda SI, Kato T, Kiyono T, Takeshita F, Kajiyama H, Kikkawa F, Ochiya T (2017) Malignant extracellular vesicles carrying MMP1 mRNA facilitate peritoneal dissemination in ovarian cancer. Nat Commun 8:14470
Yoshida M, Taguchi A, Kawana K, Adachi K, Kawata A, Ogishima J, Nakamura H, Fujimoto A, Sato M, Inoue T et al (2016) Modification of the tumor microenvironment in KRAS or C-MYCinduced ovarian cancer-associated peritonitis. PLos ONE 11: e0160330

Young RH (2006) From krukenberg to today: the ever present problems posed by metastatic tumors in the ovary: part I. Historical perspective, general principles, mucinous tumors including the krukenberg tumor. Adv Anat Pathol 13:205-227

Zhang L, Conejo-Garcia JR, Katsaros D, Gimotty PA, Massobrio M, Regnani G, Makrigiannakis A, Gray $H$, Schlienger K, Liebman MN et al (2003) Intratumoral T cells, recurrence, and survival in epithelial ovarian cancer. New Engl J Med 348:203-213

Zhang T, Ma Z, Wang R, Wang Y, Wang S, Cheng Z, Xu H, Jin X, Li W, Wang $X$ (2010) Thrombin facilitates invasion of ovarian cancer along peritoneum by inducing monocyte differentiation toward tumor-associated macrophage-like cells. Cancer Immunol Immunother 59:1097-1108

Zhang Y, Tang H, Cai J, Zhang T, Guo J, Feng D, Wang Z (2011) Ovarian cancer-associated fibroblasts contribute to epithelial ovarian carcinoma metastasis by promoting angiogenesis, lymphangiogenesis and tumor cell invasion. Cancer Lett 303:47-55

Zhang YL, Dong WH, Wang JJ, Cai J, Wang ZH (2017) Human omental adipose-derived mesenchymal stem cell-conditioned medium alters the proteomic profile of epithelial ovarian cancer cell lines in vitro. Oncotargets Ther 10:1655-1663

Zhou Y, Xu Y, Chen LJ, Xu B, Wu CP, Jiang JT (2015) B7-H6 expression correlates with cancer progression and patient's survival in human ovarian cancer. Int J Clin Exp Pathol 8:94289433

Zhu QY, Wu XL, Wu YQ, Wang XP (2016) Interaction between Treg cells and tumor-associated macrophages in the tumor microenvironment of epithelial ovarian cancer. Oncol Rep 36:3472-3478 